\title{
Optimisation of injection-related parameters by using the NLPQL algorithm for a marine medium-speed diesel engine
}

\author{
Nao Hu ${ }^{1,2}$, Jianguo Yang ${ }^{1,3}$, Peilin Zhou $^{2}$
}

${ }^{1}$ School of Energy and Power Engineering, Wuhan University of Technology, 430063, Wuhan, PRC;

${ }^{2}$ Department of Naval Architecture, Ocean and Marine Engineering, University of Strathclyde, G4 0LZ, Glasgow, UK;

${ }^{3}$ Key Laboratory of Marine Power Engineering \&Technology, Ministry of Communications, 430063, Wuhan, PRC;

\section{Abstract}

The match of an injector with the combustion chamber was studied under four different engine loads. Four design parameters including the start of injection, the spray angle, the injector protrusion length and the swirl ratio were examined. The Latin hypercube together with a NLPQL algorithm were used in the optimisation. Comparisons were made in the engine loads in terms of the optimisation history, objectives, sub-objectives and design parameters. The commonalities of the design parameters of the optimums were summarised. Additionally, a detailed combustion process comparison was conducted on the same engine loads (100\% and $25 \%$ engine loads) between the optimum and the baseline design, respectively. Finally, the effects of the design parameters on the objective were investigated by the RSM. The results indicate that the NLPQL method is an effective algorithm to spot the optimums with the best trade-off between the NOx and soot emissions. The optimisation process presents better qualities at the $100 \%$ and $75 \%$ engine loads than at the case of the $50 \%$ and $25 \%$ engine loads. The design parameters of the optimum under each engine load have something in common, namely that they all prefer the late injection, low swirl, large injection angle and slightly smaller nozzle protrusion length. Besides, the start of injection and the swirl ratio have larger influences on the objective as opposed to the nozzle protrusion length and spray angle. The large start of injection together with the small swirl ratio can reduce the objective significantly and vice versa. A large nozzle protrusion length with a small spray angle contributes to the reduction of the objective; and so does the combination of a small nozzle protrusion length with a large spray angle.

\section{Keywords}

injection-related parameters; emissions; optimisation; NLPQL algorithm; engine load 


\begin{tabular}{|c|c|c|c|}
\hline \multicolumn{4}{|c|}{ Nomenclature } \\
\hline ATDC & after top dead centre & RSM & response surface methodology \\
\hline BSEC & brake specific energy consumption & SA & spray angle \\
\hline BTDC & before top dead centre & SFOC & specific fuel oil consumption \\
\hline BTE & brake thermal efficiency & Sobol & $\begin{array}{l}\text { quasi-random low-discrepancy } \\
\text { sequences }\end{array}$ \\
\hline CFD & computational fluid dynamics & SOI & start of injection \\
\hline CIDI & compression-ignition direct-injection & SQP & sequential quadratic programming \\
\hline $\mathrm{CO}$ & carbon monoxide & SR & swirl ratio \\
\hline $\mathrm{CO} 2$ & carbon dioxide & SS-ANOVA & smoothing spline analysis of variance \\
\hline DI & direct injection & $\mathrm{TDC}$ & top dead centre \\
\hline DIESEL-D1 & light diesel fuel oil & $\mu \mathrm{GA}$ & micro-genetic algorithm \\
\hline DoE & design of experiment & & \\
\hline EGR & exhaust gas recirculation & \multicolumn{2}{|c|}{ Functions and variables } \\
\hline GA & genetic algorithm & $x$ & $\mathrm{n}$-dimensional parameter vector \\
\hline $\mathrm{HC}$ & hydrocarbons & $\mu_{i}$ & weight \\
\hline KIVA & a Fortran-based CFD software & $\mathrm{E}$ & set \\
\hline k-zeta-f & turbulence model & $f$ & function \\
\hline L100 & $100 \%$ engine load & $g_{j}$ & constraints \\
\hline $\mathrm{L} 25$ & $25 \%$ engine load & $j$ & variable \\
\hline L50 & $50 \%$ engine load & $m$ & maximum value of $j$ \\
\hline L75 & $75 \%$ engine load & $m_{e}$ & real number \\
\hline LDC & lower dead centre & $O_{i}$ & objectives of merit function \\
\hline MOGA & multi-objective genetic algorithm & $R^{n}$ & n-dimensional real space \\
\hline$n$ & number of level & $x_{Q}$ & lower bound of $x$ \\
\hline$n^{k}$ & number of combination & $x_{u}$ & upper bound of $\mathrm{x}$ \\
\hline$n !$ & number of permutations & & \\
\hline NLPQL & $\begin{array}{l}\text { non-linear programming by quadratic } \\
\text { Lagrangian }\end{array}$ & Units & \\
\hline $\mathrm{NN}$ & neural networks & bar & pressure unit \\
\hline NOx & nitrogen oxides & CAD & crank angle degrees \\
\hline NOx_b & NOx emissions of the baseline design & deg & degree \\
\hline Soot_b & Soot emissions of the baseline design & $\mathrm{g} / \mathrm{kWh}$ & grams per kilowatt-hour \\
\hline SFOC_b & SFOC emissions of the baseline design & $\mathrm{L}$ & litre \\
\hline NPL & nozzle protrusion length & $\mathrm{k}$ & kilo \\
\hline NSGA-II & non-dominated sorting genetic algorithm II & $\mathrm{kW}$ & kilo Watt \\
\hline Piso & pressure implicit split operator & $\mathrm{mm}$ & millimetre \\
\hline
\end{tabular}




\section{Introduction}

Marine diesel engines are extensively used for ship propulsion due to their high reliability and fuel economy. However, the intolerable pollution caused by them is gaining increased attentions worldwide. Compared to automotive diesel engines, its $\mathrm{CO}, \mathrm{CO} 2$ and $\mathrm{HC}$ emissions are much lower, whereas the NOx emissions are severely deteriorated. Although after-treatment devices are frequently applied in order to reduce the NOx emissions, the optimisation of the in-cylinder combustion process is still of great significance. However, combustion is very susceptible to the match status of the fuel injector and combustion chamber. Prominent works have already been carried out in this domain. Taghavifar et al. [1] studied the effects of the bowl movements and radius on the mixture formation in terms of the homogeneity factor, combustion initiation and emissions for a $1.8 \mathrm{~L}$ Ford diesel engine. Four different combustion chamber shapes were designed in each bowl movement direction, where the bowl radius and outer bowl diameter were increased. They pointed out that the mixture uniformity increased in line with the bowl displacement toward the cylinder wall, but conversely experienced an increase in the combustion delay, which substantially reduced the effective in-cylinder pressure. Mobasheri et al. [2] investigated the influence of a re-entrant combustion chamber geometry on mixture formation, combustion and performance for a high-speed direct injection diesel engine. Thirteen combustion chambers with different shapes were designed by adjusting the piston parameters, i.e. bowl depth, bowl width, piston bottom surface and the lip area. References [3-7] developed a KIVA code with $\mu$ GA, MOGA or NSGA-II in order to study the matching of a variety of injection-related parameters and combustion chamber geometries. A significant amount of optimisation work was completed from small bore high-speed direct injection engines to heavy-duty large bore slow-speed diesel engines $[3,4,5,6,7]$.

In practical applications, however, it is much easier to adjust the injection-related parameters, such as the injection timing, injection angle, injector protrusion length and swirl ratio, than modify the combustion chamber geometries in order to improve the engine performance and achieve a lower emission level. This makes the importance of the fuel injection-related parameters more prominent. Beatrice et al. [8] studied the effects of the most important injection settings on the engine performance and emissions of a $2.0 \mathrm{~L}$ Euro 5 diesel engine when using the two fuel blends. A DoE method was applied. The results indicated that the pilot injection quantity and rail pressure value are the most influential factors in the gaseous unburned reduction. Combustion phasing and the dwell time are positive to the unburned gaseous reduction but negative to the combustion noise. Pandian et al. [9] investigated the effects of the injection-related parameters, such as the injection pressure, injection timing and the nozzle protrusion length on the performance and emission characteristics of a twin cylinder water cooled naturally aspirated CIDI engine. The RSM was built by DoE in order to predict the brake specific energy consumption (BSEC), brake thermal efficiency (BTE), carbon monoxide (CO), hydrocarbon (HC), smoke opacity and NOx. The results showed that the BSEC, CO, HC and smoke opacity were lower, and that the BTE and NOx were higher with the combination of $2.5 \mathrm{~mm}$ nozzle tip protrusion, $225 \mathrm{bar}$ injection pressure and 30 degree BTDC of injection timing. 
Emissions and fuel economy are always a pair of irreconcilable contradictions.

Therefore, the GA is frequently used for finding an optimum with the best trade-off between them, as already stated previously. Nevertheless, even a single run of a combustion CFD case is time consuming, for example, a period of four and a half hours is needed when a case is calculated by a single core Inteli7-4790 CPU@3.6 GHz, needless to say how much time it will take when there are hundreds of cases in a GA optimisation process. Recently, the NLPQL algorithm was introduced for the engine combustion optimisation in only a few studies. The performance thereof is more attracitve due to a reduced time consumption with optimal designs found not bad than the GA. Chen et al. [10] optimised four injection-related parameters and three combustion chamber geometry parameters of an $8.9 \mathrm{~L}$ Cummins diesel engine. The NLPQL algorithm was applied to optimise the three re-entrant combustion chamber geometries in detail, while the injection-related parameters were not included. Navid et al. [11] compared the GA and the NLPQL algorithms when they were used for optimising a Ford 1.8L DI engine. A re-entrant combustion chamber was involved. The results indicated that the NLPQL algorithm was effective in optimising four factors including the injection angle, half spray cone angle, the inner distance of the bowl wall and the bowl radius by approaching an optimal design faster than the GA. Both references [10-11] deal with the optimisation of the re-entrant combustion chambers. Interestingly, $\mathrm{Hu}$ et al. [12] compared the performance of an NLQPL algorithm and a GA and later combined them together. Both algorithms were checked with the purpose of optimising seven engine design parameters (the injection timing, the spray angle, the nozzle protrusion length, the swirl ratio, the bowl diameter, the centre crown height and the toroidal radius). They implied that the performance of the NLPQL algorithm may be satisfactory with significantly fewer runs by properly choosing the start point. Yet these studies deal with the optimisation with combustion chambers under a specific engine load, the performance of NLPQL algorithm, the differences and commonalities in the optimums of different engine loads were not revealed.

The RSM is frequently used as the tool to analyse the sensitivity of the design parameters on the objectives (NOx, soot and SFOC) $[5,6,9]$. It uses an approximation model in order to analyse the data generated by the DoE method. Several functions can be used for building approximation models, such as polynomials, SS-ANOVA, NN [13, 14], etc. The SSANOVA $[6,9,15,16]$ was frequently adopted in many engine optimisation tasks.

In this study, the NLPQL algorithm was adopted in order to optimise the four injection-related parameters matching with a shallow basin shape combustion chamber under four different engine operating loads. Firstly, the optimisation process was compared under four different engine loads in terms of optimisation history, objectives, sub-objectives and design parameters. Secondly, the detailed combustion process was disclosed by comparing the baseline design with the optimal designs of the L100 and L25 engine loads, since they have the largest and smallest NOx emissions reductions respectively. Then, the effects and interactions of the design parameters on the objective were investigated through RSM.

\section{Optimisation algorithms}


It is commonly known that the NLPQL algorithm is a local optimisation method, associated with a local optimum. In order to overcome this disadvantage, the Latin hypercube design is adopted before the NLPQL design.

\subsection{Latin hypercube design}

In Latin hypercube design, the design space of each factor or design parameter was divided into $n$ levels uniformly. On each level of every factor, only one design point is placed. For each factor, $n$ ! permutations of the $\mathrm{n}$ levels are possible. The design matrix of the Latin hypercube consists of one column for each factor and the column is determined by a randomly chosen permutation of the $n$ levels. For a row in the design matrix, $n^{k}$ combinations are possible and have an equal chance of occurring. As the matrix is generated randomly, the correlation between the columns may exist [17].

\subsection{NLPQL algorithm}

NLPQL was developed by Klaus Schittkowski [18] for solving the nonlinear programming problem.

$\min f(\mathrm{x})$

$$
\begin{gathered}
g_{j}=0, j=1, \ldots, m_{e} \\
x \in R^{n}: g_{j}(x) \geq 0, j=m_{e}+1, \ldots, m \\
x_{Q} \leq x \leq x_{u}
\end{gathered}
$$

Where, $x$ is the n-dimensional parameter vector. $x_{Q}$ and $x_{u}$ are the lower bound and upper bound of $x . f(x)$ is the problem function. $g_{j}(x)$ are the constraints of the problem.

The optimisation method generates a sequence of quadratic programming subproblems which are to be solved successively. The method is therefore known as the SQP method. It assumes that objective functions and constraints are continuously differentiable on the set $E=\left\{x \in R^{n}: x_{Q} \leq x \leq x_{u}\right\}$. Note that the functions f and $g_{j}, j=1, \ldots, m$ need to be defined only in the set $E$, since the iterations computed by the algorithm will never violate the lower and upper bounds.

If NLPQL algorithm is used to solve a multi-objective problem, a merit function with a weighted sum method must be adopted to transfer it to a single objective optimisation problem. The formula of weight sum method is

Objective $=\sum_{i=1}^{k} \mu_{i} O_{i}(x)$

In (2), $\mu_{i}$ is the weight of each objective, which is decided by researchers according to their experiences, $O_{i}$ are the sub-objectives. 
In this paper, the merit function is built in (3) to reduce the NOx and Soot emissions, and minimise the fuel consumption rate as well. The weights are given according to experience [10].

Objective $=\left(\frac{\mathrm{NOx}}{\mathrm{NOx}_{-} \mathrm{b}}\right) * 5+\left(\frac{\text { Soot }}{\text { Soo__ } \mathrm{b}}\right) * 1+\left(\frac{\text { SFOC }}{\text { SFOC_b }}\right) * 3$

Where, NOx_b, Soot_b, SFOC_b are the NOx emissions, soot emissions and SFOC of the baseline design. The NOx emissions, soot emissions and SFOC to the value of baseline design are regards as the three sub-objectives here.

\section{Preparation}

\subsection{Engine specifications}

The main specifications of the marine medium-speed diesel engine and fuel injectors are presented in Table 1. It is an in-line type, four-stroke diesel engine with six cylinders. Its rated speed and rated powers are $1000 \mathrm{rpm}$ and $540 \mathrm{~kW}$, respectively. The spray orifice distribution of the original injector of the mechanical fuel injection system is $9 * 0.28 \mathrm{~mm}$, which is replaced by an electronic fuel injector of $9 * 0.23 \mathrm{~mm}$ for the performance and emission prediction study.

Table 1 Specifications of the engine and fuel injectors

\begin{tabular}{ll}
\hline Specifications & Value \\
\hline Engine name & $\begin{array}{l}\text { MAN } \\
\text { 6L16/24 }\end{array}$ \\
Cylinder arrangement & In-line \\
Number of stroke & 4 \\
Bore $(\mathrm{mm})$ & 160 \\
Stroke(mm) & 240 \\
Number of cylinders & 6 \\
Rated speed (r/min) & 1000 \\
Rated power (kW) & 540 \\
SFOC (g/kWh) & 189 \\
Compression ratio & 15.2
\end{tabular}


Original injector $\quad 9 * 0.28 \mathrm{~mm}$

Electronic fuel injector $\quad 9 * 0.23 \mathrm{~mm}$

\subsection{Simulation models}

Simulations were conducted by using a series of the AVL FIRE software. Firstly, a combustion chamber at the TDC moment was drawn in the FIRE 2D Sketcher software according to the shape of the upper surface of the piston and the clearance distance between the piston surface and the cylinder head. Secondly, the design combustion chamber geometries were loaded in the FIRE ESE Diesel software in order to build a CFD model. In this instance, the k-zeta-f $[19,20]$ turbulent model for high Reynolds numbers is adopted to describe the flow field inside a combustion chamber. Stand wall function was used to describe heat transfer of wall. Piso algorithm [21, 22] is adopted here to solve the highly unsteady-state flow of the combustion problem. In terms of the fuel spray model, the Dukowicz [23] model was applied for handling the heat-up and evaporation of the fuel oil droplets. Moreover, Wave [24, 25] break-up model and Walljet1[26, 27] wall interaction model are used respectively. The Eddy break-up model $[28,29]$ is introduced in the calculation of combustion. With regard to emission models, an extended Zeldovich [30] mechanism was adopted for the NOx emission model while a Kinetic mechanism for the soot emission model $[31,32,33]$. Once the CFD model is validated, it can be used for a multiobjective study. Thus, the CFD model was loaded in the FIRE DVI software, where the calculation settings were specified. Then, the FIRE Design Explorer software was invoked, where the design variables and their variation ranges, objectives, constraints and algorithms were defined or selected. Finally, the combustion images were processed in the FIRE Workflow Manager software. The complete scheme of the software used in the study is shown in Fig. 1. 


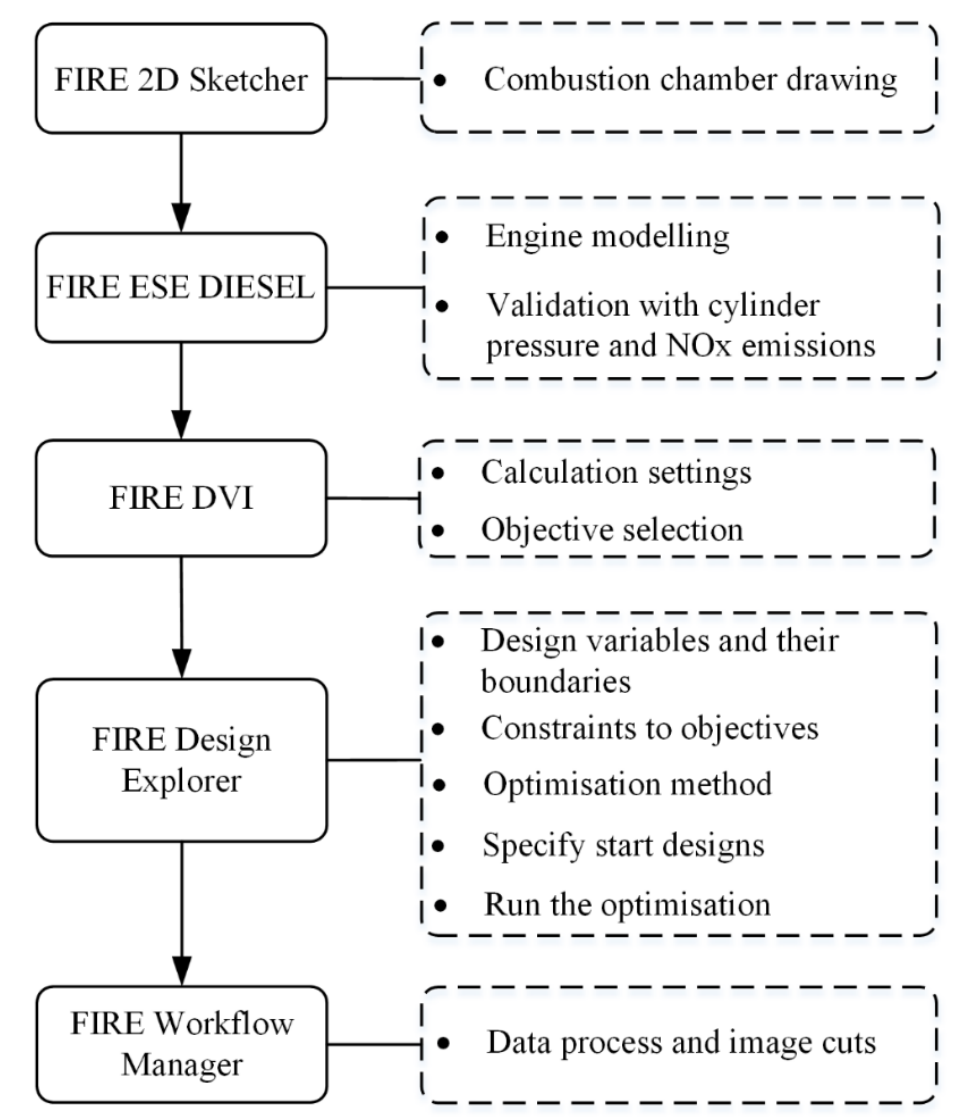

Fig. 1 The scheme of a series of the FIRE software used in the study

\subsection{Model verification}

A FIRE simulation model of the original diesel engine was executed on the condition of rated engine speed and four engine loads. Light diesel oil (represented by DIESEL-D1 in AVL Fire software) is used in the calculation. In order to improve the convergence at the beginning of the calculation, the initial calculation step is set to 0.2 CAD. Then, $1 \mathrm{CAD}$ is adopted at the compression stroke in order to accelerate calculation and save time as well. However, at the injection stage, the precision is emphasised by reducing the calculation step to $0.2 \mathrm{CAD}$ again. In the expansion combustion stage, the $0.5 \mathrm{CAD}$ calculation step is adopted. With regard to average mesh size, Abraham [34] recommended the mesh size to be on the same length scale with nozzle diameter. Thus, the average mesh size is set to $1 \mathrm{~mm}$, totally $125 \mathrm{k}$ cells were calculated. Fig. 2 shows the mesh of original combustion at 0 CAD (TDC), 64.5 CAD and 180 CAD (LDC), which are described by (a), (b) and (c) in Fig. 2 respectively. The mesh at TDC has minimum cell numbers of 4063 while the mesh at LDC has maximum cell numbers of 15833 . 


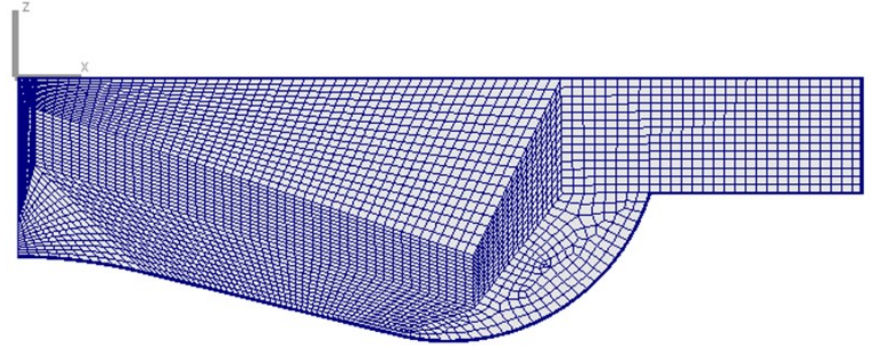

(a)

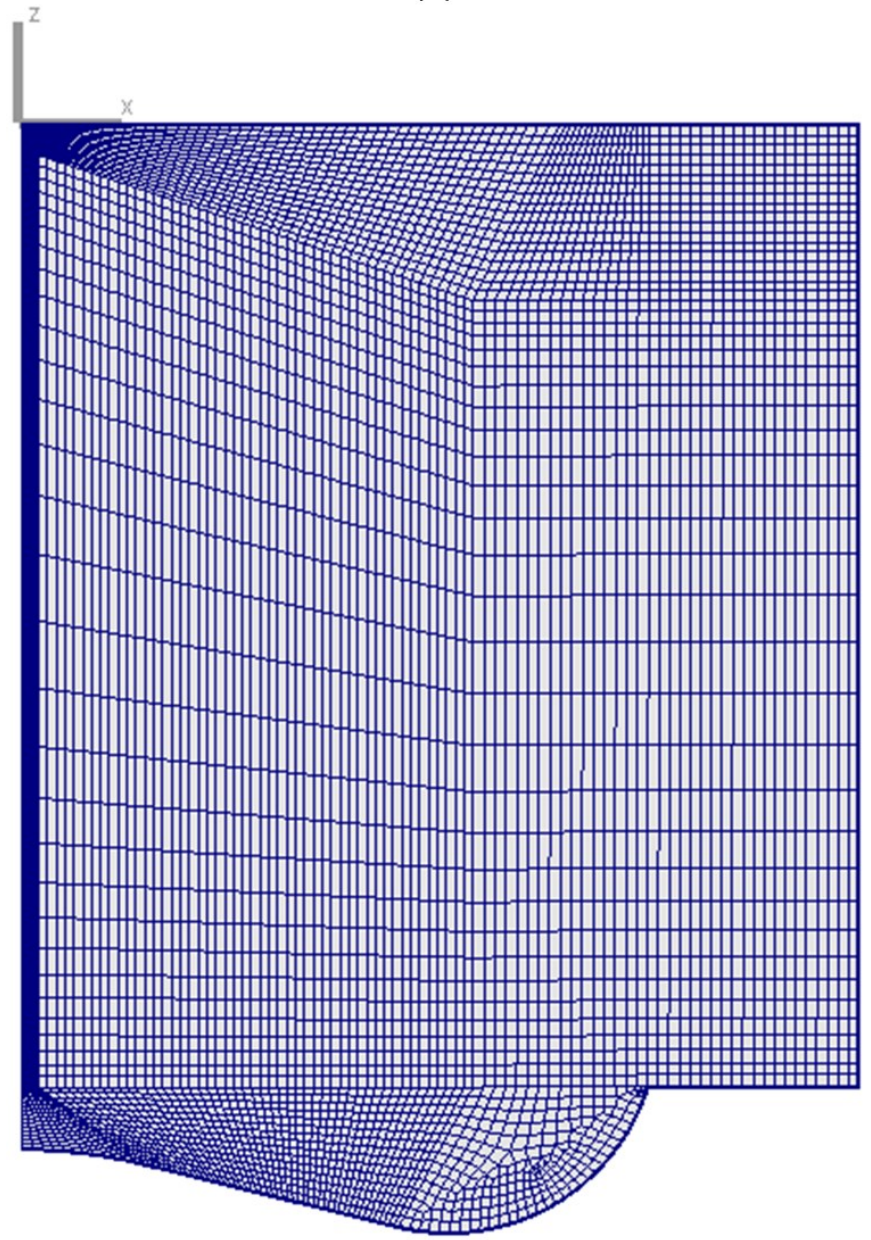

(b)

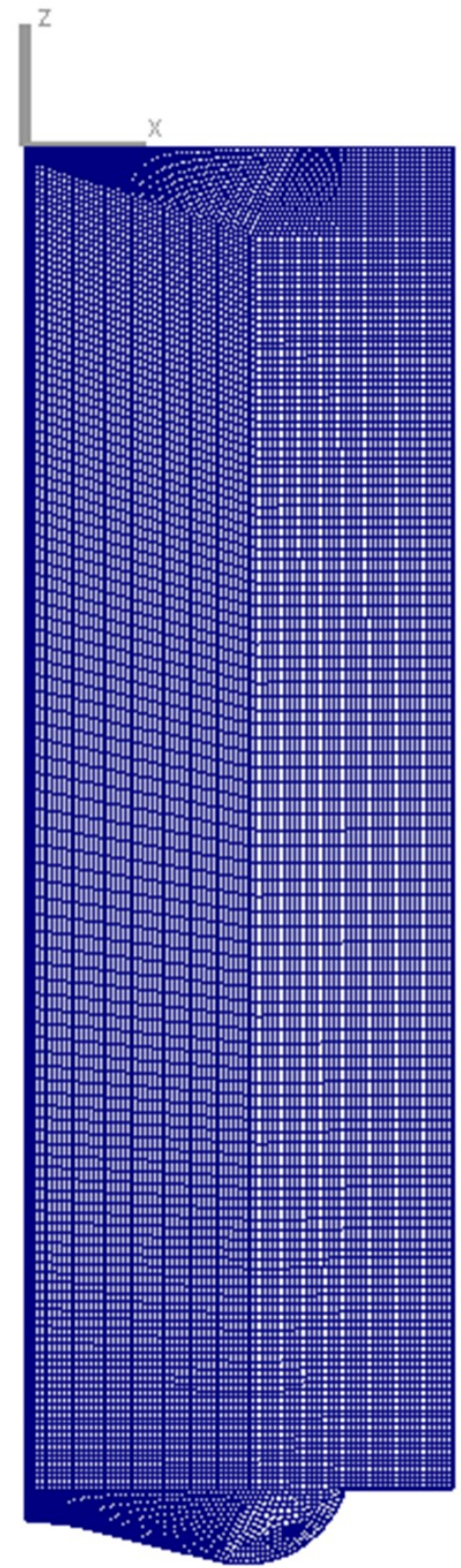

(C)

Fig. 2 Mesh changes with piston movements

The comparisons of the cylinder pressures between the simulation data and the test data of each engine load are shown in Fig. 3. It can be seen that a good agreement of simulation data and experimental data under each load is achieved, especially at the 
combustion stage. At the compression and expansion stages, the simulation data was a little bit larger than the test data, that's because the pressure losses induced by leakage were not considered in the simulation model, while these losses do exist in the authentic diesel engines.
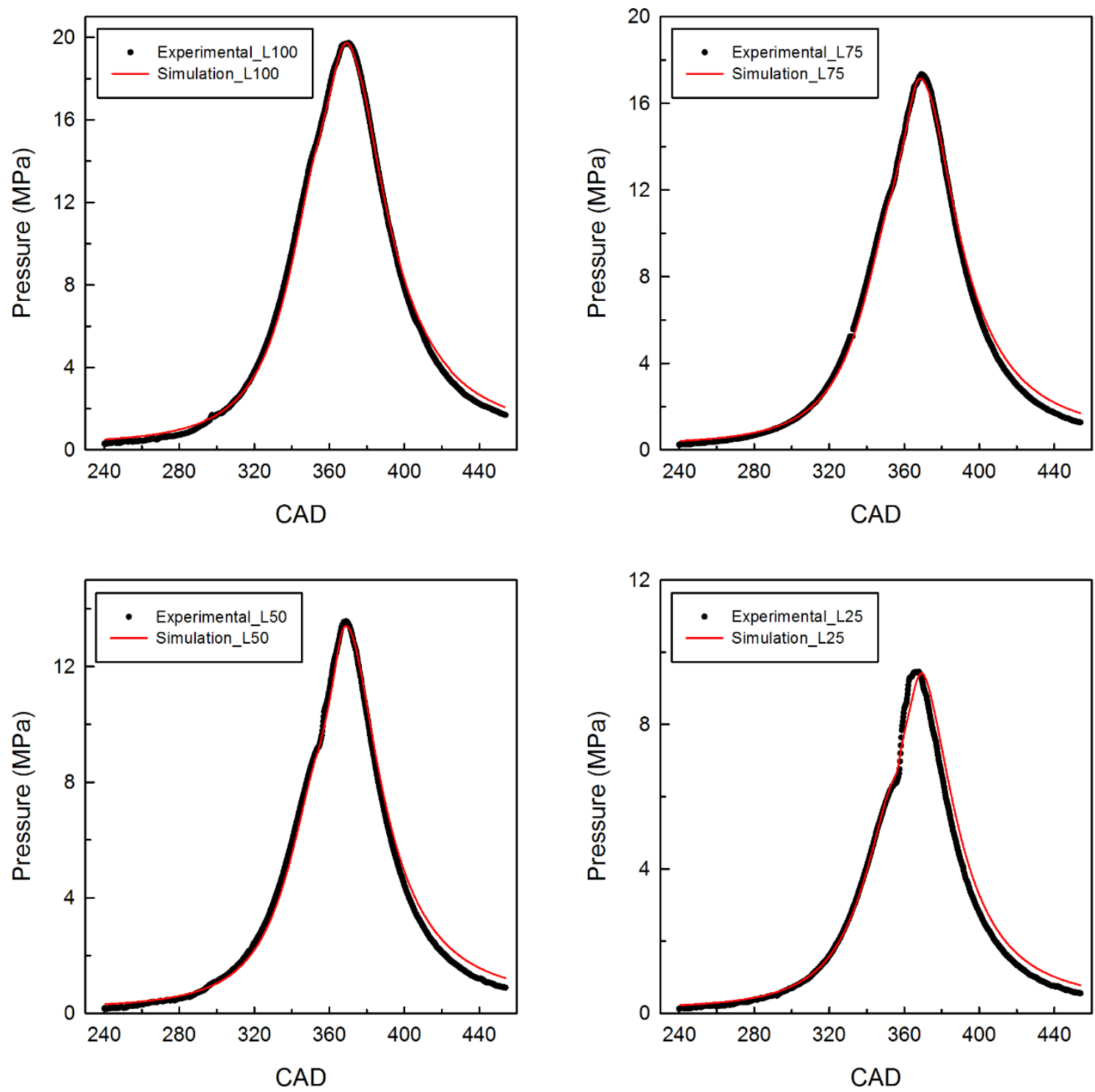

Fig. 3 Pressure comparisons of the experimental data and the simulation data of each engine load

NOx emissions are also examined and compared at each engine load. As shown in Fig. 4, the main trend of simulation results corresponds to the experimental data. The maximum error occurred at full load which is less than $6.5 \%$. 


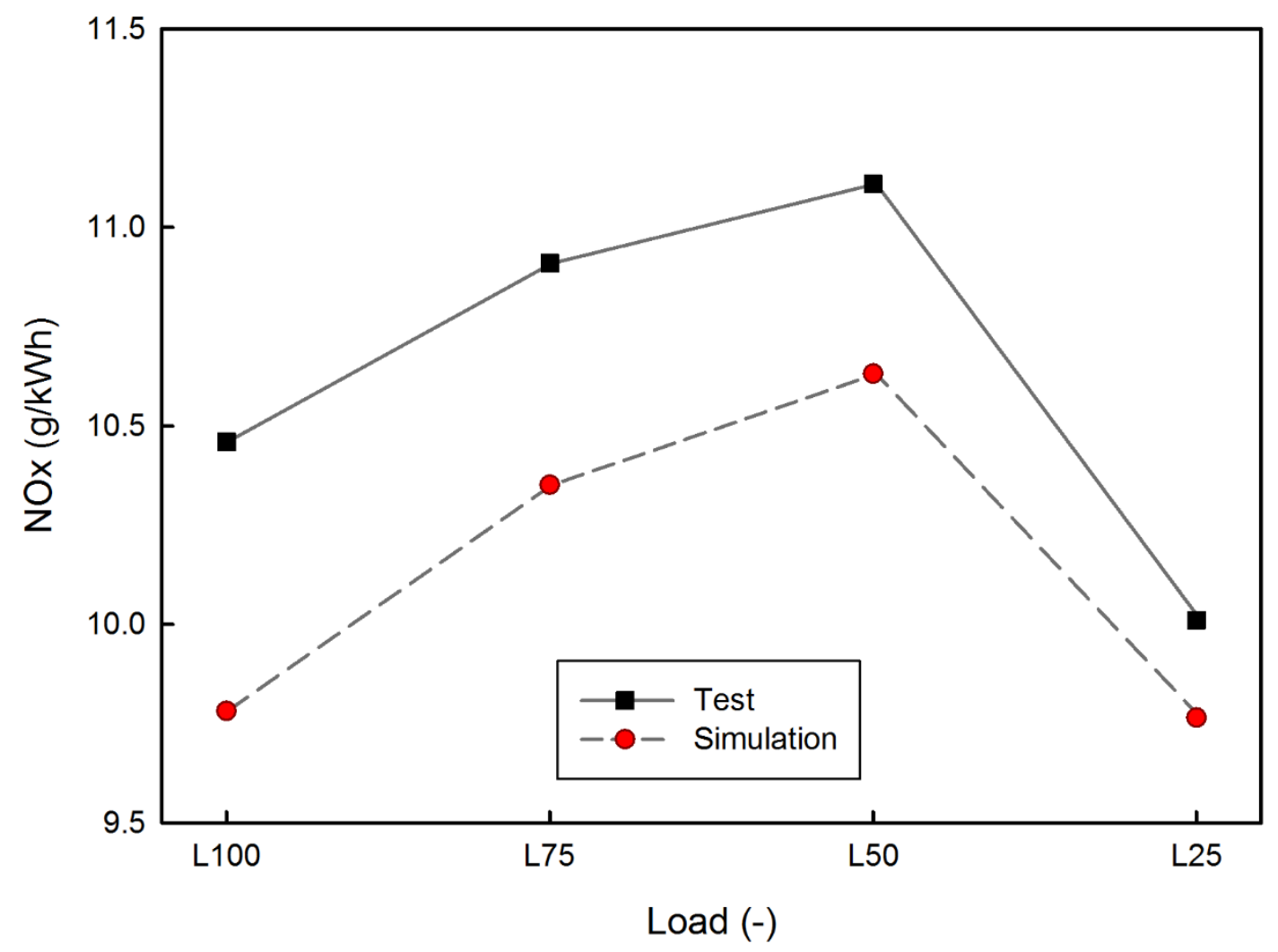

Fig. 4 NOx emission comparison of test data and simulation data of four engine loads

Verification indicates that the model can be used to simulate and predict the engine performance when replacing the original mechanical fuel injection by a high-pressure common rail injection system. The engine body with the high-pressure common rail fuel injection system is considered as the baseline design, which kept the match parameters the same as the original one.

\subsection{Design parameters and their constrains}

The design parameters and their constraints are shown in Table 2.

Table 2 Design parameters and constraints

\begin{tabular}{llll}
\hline Parameters & Baseline & Lower bound & Upper bound \\
\hline SOI, CA & 710 & 700 & 720 \\
SR, - & 1.0 & 0.5 & 2.5 \\
SA, deg & 143 & 131 & 155
\end{tabular}


NPL, mm $\quad 2.5 \quad 1.0 \quad 4.0$

\subsection{Optimisation settings}

The optimisation settings of the NLPQL algorithm are listed in Table 3.

Table 3 Optimisation setting of the NLQPL algorithm

\begin{tabular}{ll}
\hline Property & Value \\
\hline Maximum number of function evaluations & 5 \\
Maximum number of iterations & 20 \\
Step size for finite difference step & 0.001 \\
Accuracy & $1 \mathrm{e}-05$ \\
\hline
\end{tabular}

\section{Results and discussion}

\subsection{Comparisons of the objectives}

Fig. 5 to Fig. 8 report the optimisation history with NLPQL algorithm of each engine load. The red vertical dashed lines indicate the position where the minimum objective of each engine load locates. The red circle points identify the history of the objectives. The ratios of the NOx, soot and SFOC to the baseline design are represented by black diamond points, blue triangle points and reversed yellow triangle points respectively. Each Run ID represents a design case.

In all of the history charts, the first 30 results of each load were searched by the Latin hypercube algorithm. This algorithm was used prior to NLPQL algorithm in order to avoid the NLPQL algorithm being trapped by a local optimum.

From Fig. 5 to Fig. 8, a maximum of 64 runs were presented in the L75 engine load, and a minimum of 52 runs occurred in the L25 engine load. Compared to the reference [11], the totals runs of the NLPQL algorithm are significantly fewer than the evolution method GA. The minimum objectives locate at the Run ID 37, Run ID 32, Run ID 32 and Run ID 6 of the L100, L75, L50 and L25 engine loads respectively. 


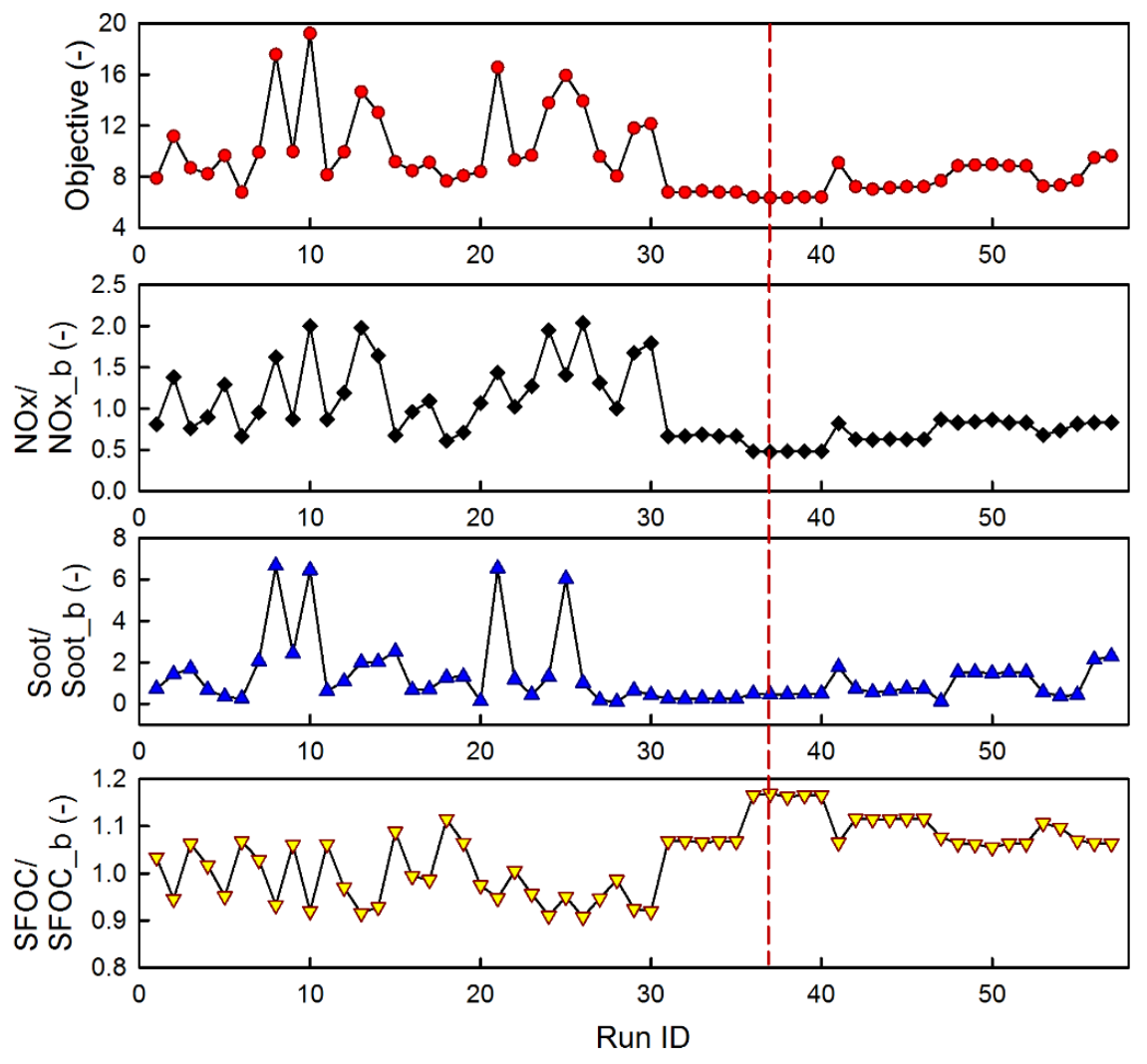

Fig. 5 Optimisation history of the L100 engine load 

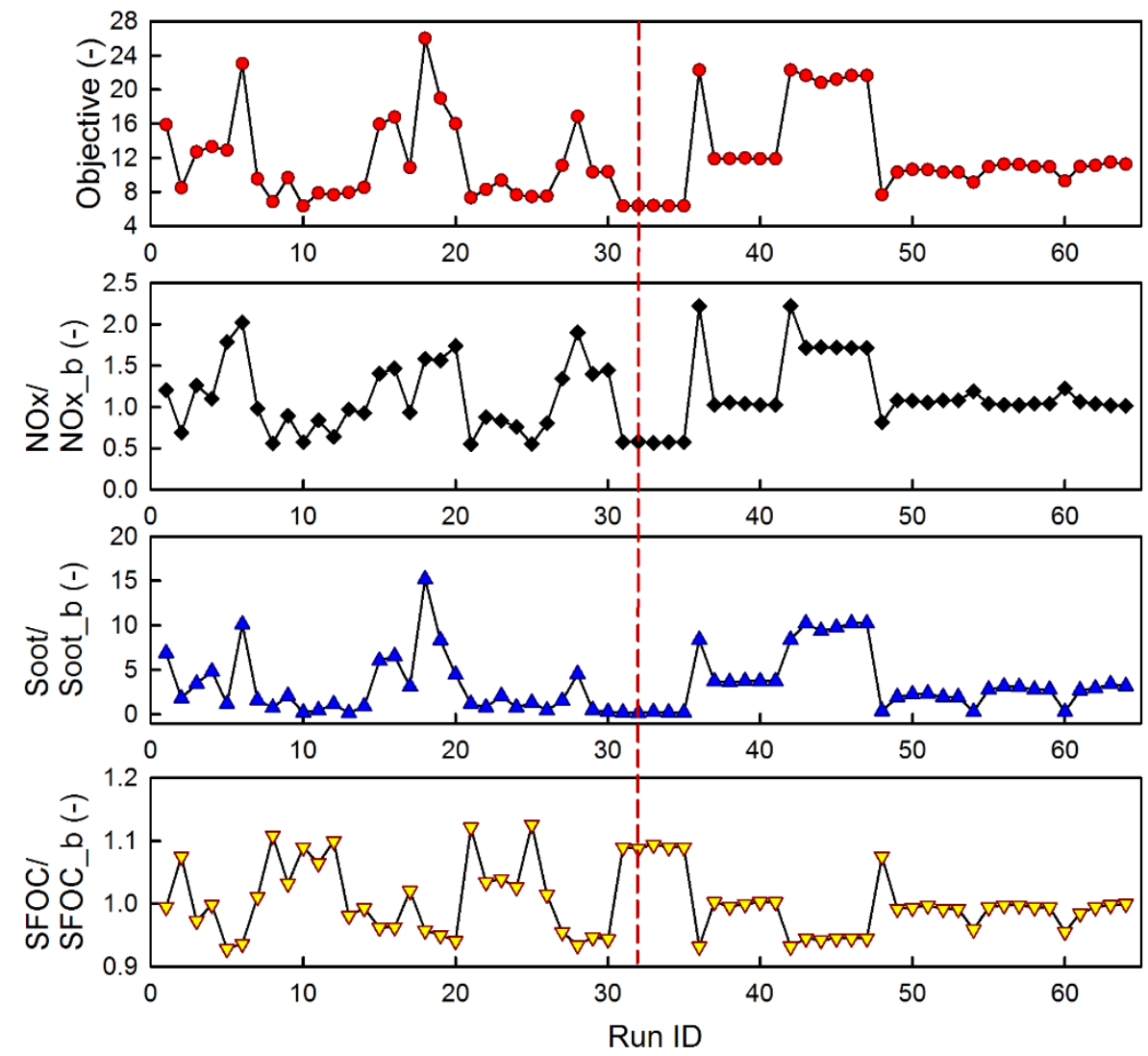

Fig. 6 Optimisation history of the L75 engine load 

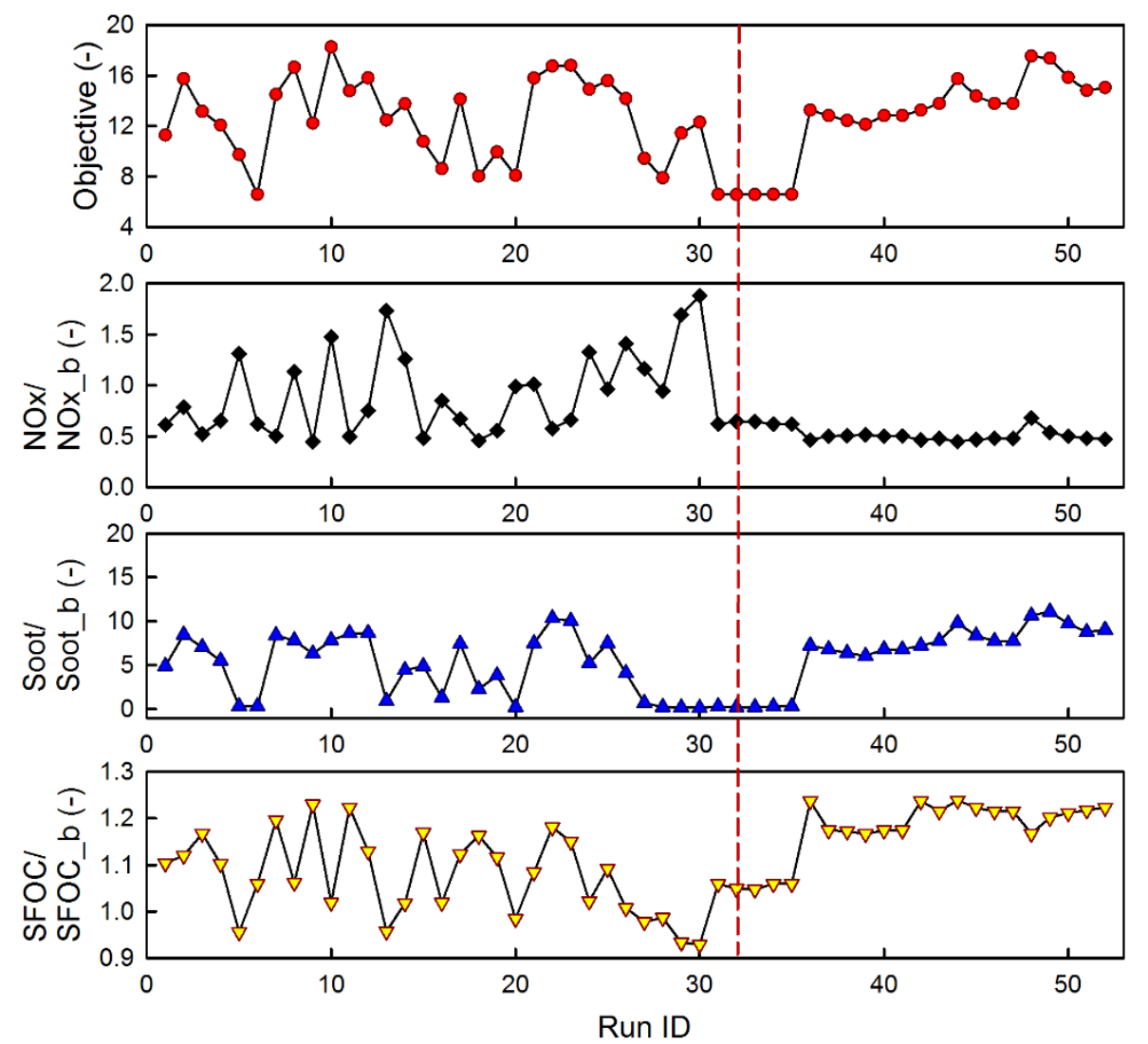

Fig. 7 Optimisation history of the L50 engine load 


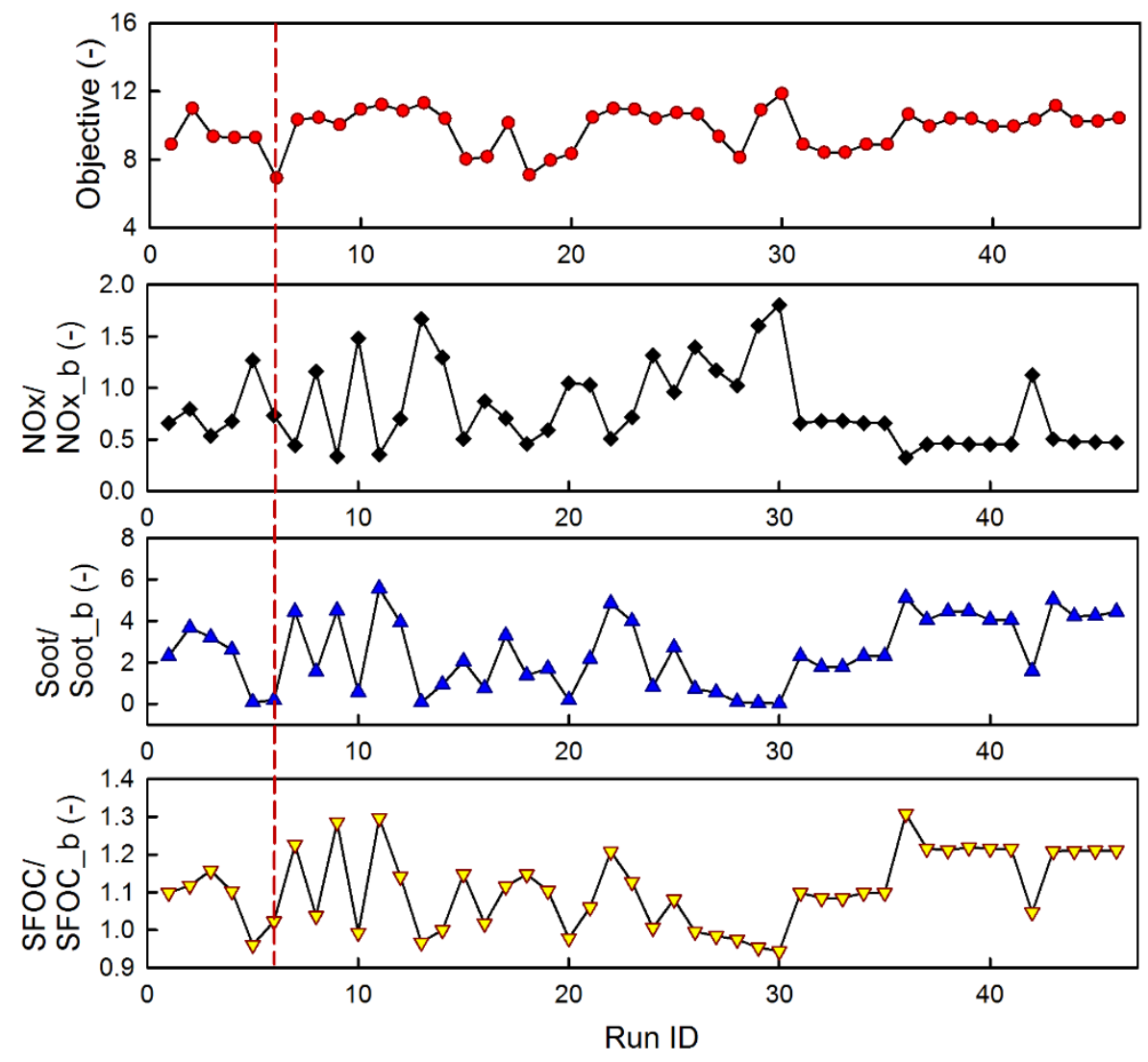

Fig. 8 Optimisation history of the L25 engine load

\subsection{Comparisons of the sub-objectives}

The scattering charts of NOx vs. soot and NOx vs. SFOC under all four engine loads are shown in Fig. 9 and Fig. 10, respectively. In the figures, the black rectangular points represent the baseline design, while the blue triangle points represent the best designs of each load.

Fig. 9 clearly shows that the NOx emissions achieved a significant reduction in all four engine loads, namely up to $43.8 \%, 35.7 \%, 32.0 \%$ and $25.0 \%$ of the L100, L75, L50 and L25 loads, respectively. The specifications were reported in Table 4 and the visualised comparisons were made in Fig. 11. However, the reduction rate decreases with the decrease in the engine loads. Soot emissions achieved an even larger reduction rate, of up to $50 \%$ in the L100 engine load and of approximately $80 \%$ in the other three engine loads. In general, the optimum of each load achieved the best trade-off between NOx and soot emissions. From this point, it can be inferred that the NLPQL algorithm is effective for the optimisation of each engine load. Yet slight differences in terms of the distribution of the solutions disclosed the optimisation quality level under different loads. In other words, most of the solutions located at the bottom left corner in Fig. 9 (a) and (b) indicate that the optimisation process 
searched around an area where an optimum with the best trade-off may locates with a larger possibility. However, Fig. 9 (c) and (d) reported that the top left corner has a larger density of the distribution of solutions, thus, the optimisation process is tilted toward the reduction of the NOx emissions. So it can be assumed that the optimisation qualities of the L50 and L25 engine loads (low engine loads) are not as good as those of the L100 and L75 engine loads (high engine loads). Evidence can also be found by the objective history of each engine load from Fig. 5 to Fig. 8.

(a)

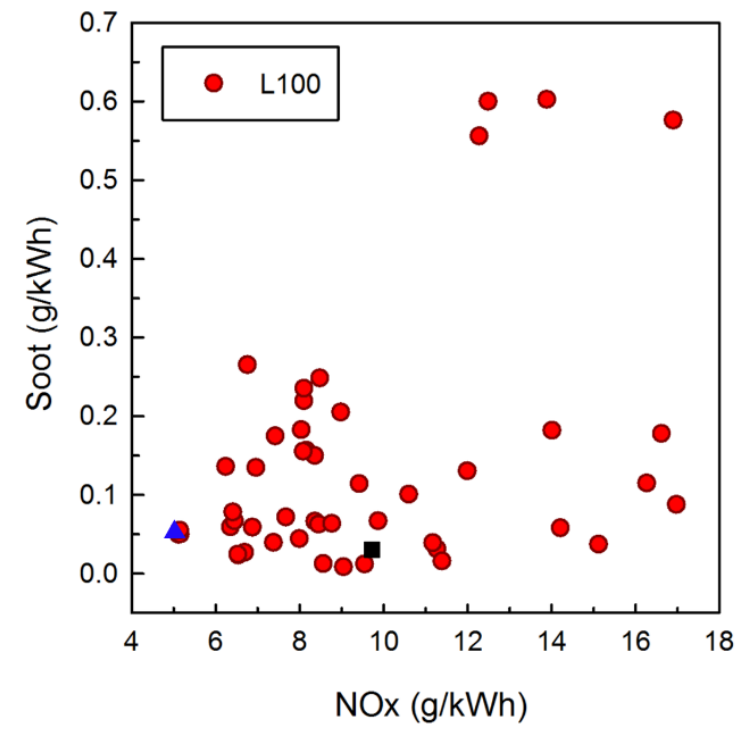

(c)

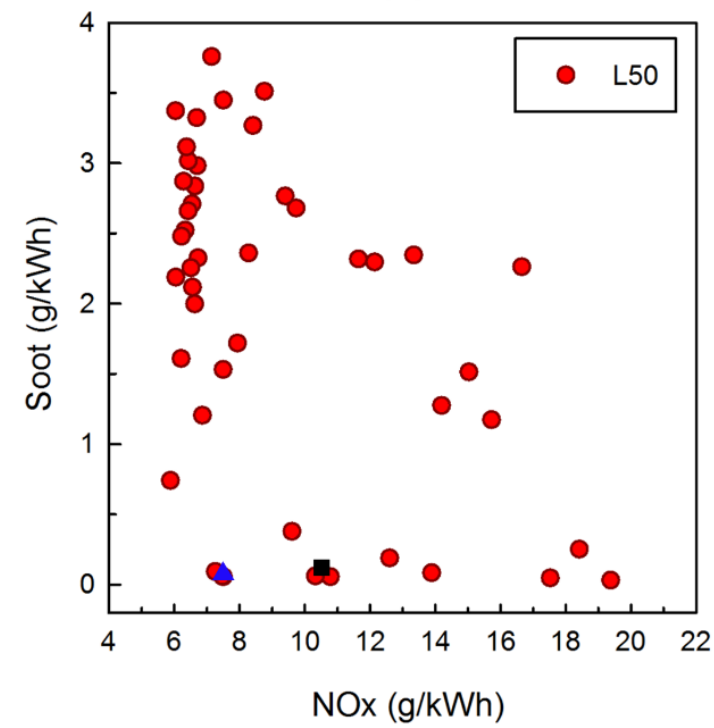

(b)

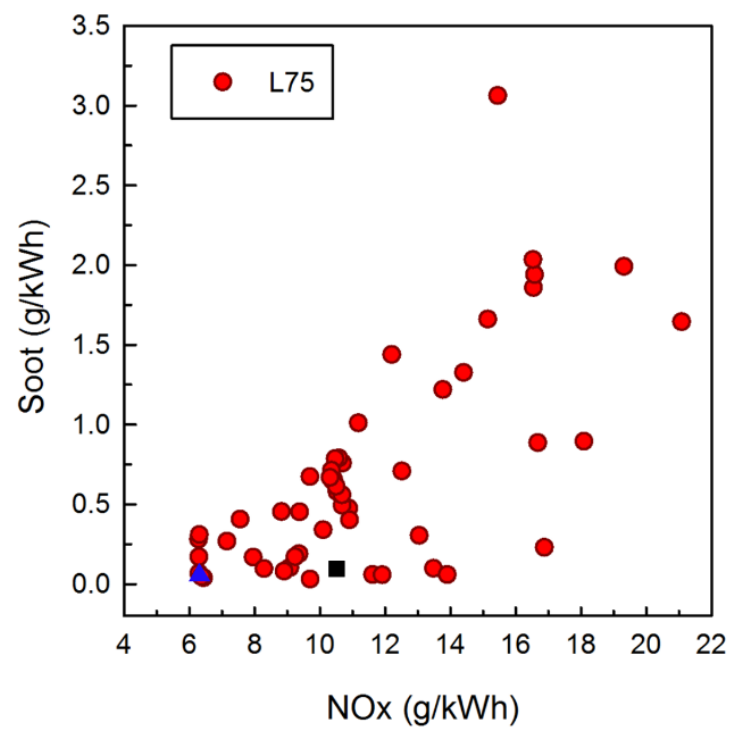

(d)

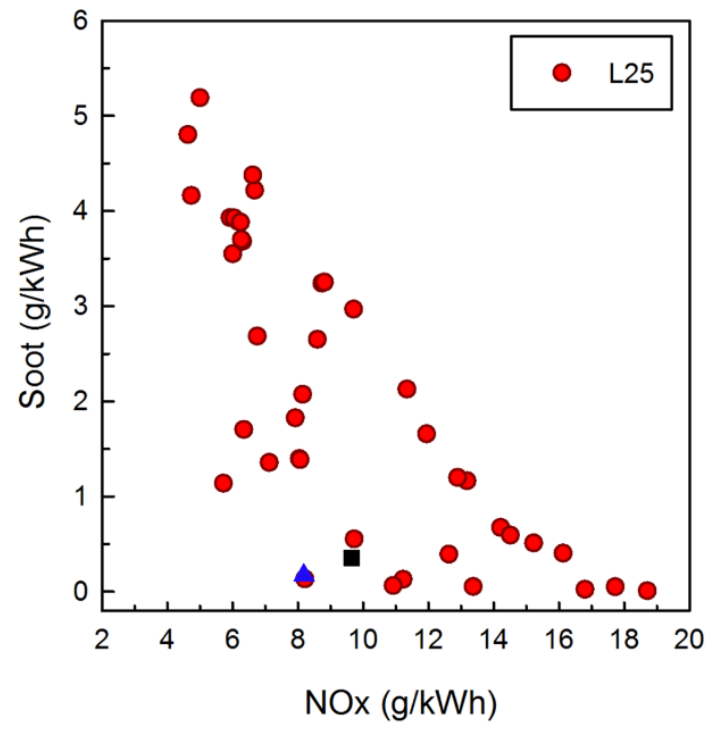

Fig. 9 NOx vs. soot of each engine load 
Fig. 10 indicates that the optimum of each engine load gets the penalties of a higher fuel consumption rate, i.e., $17.0 \%, 9.2 \%, 4.9 \%$ and $2.2 \%$ of the L100, L75, L50 and L25 engine loads, respectively. Obviously, the fuel economy penalty increases with the increase in the engine load. Combining Fig. 9 and Fig. 10, an interesting phenomenon may be observed, namely that although smaller reductions of NOx and soot emissions were achieved at low engine loads, they got lighter penalties on the fuel economy.

(a)

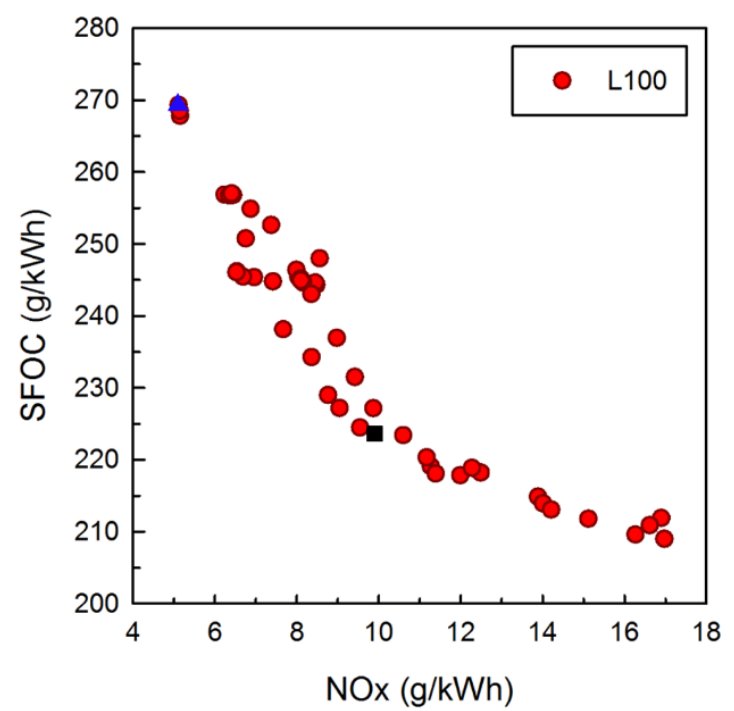

(c)

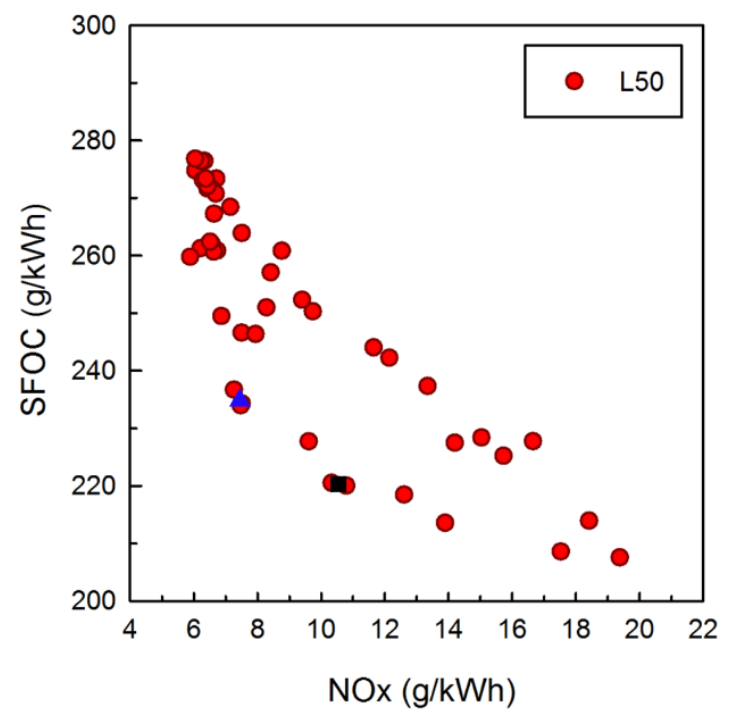

(b)

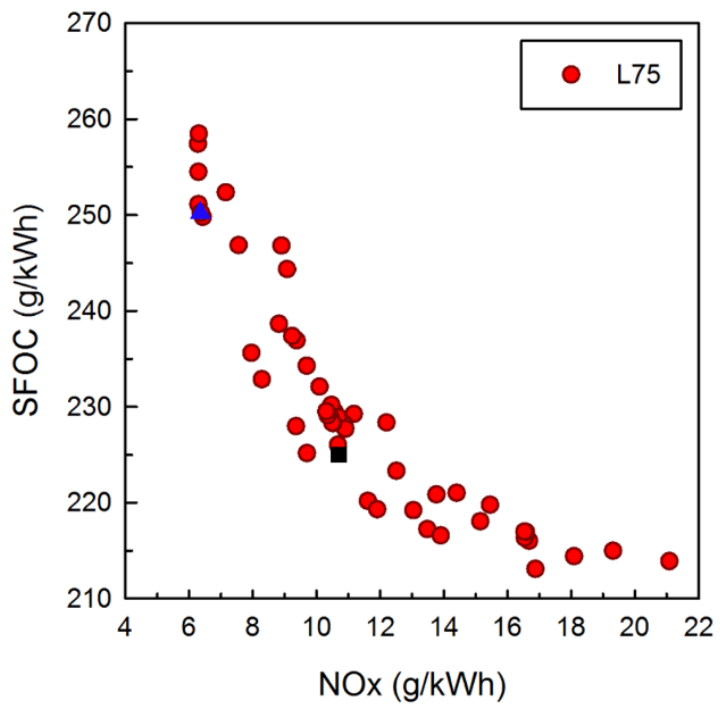

(d)

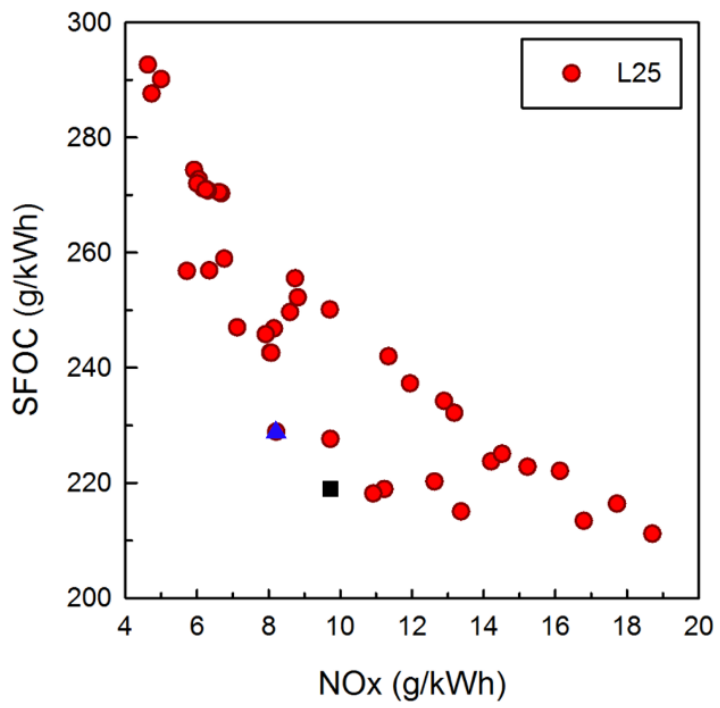

Fig. 10 NOx vs SFOC of each engine load 
(a)

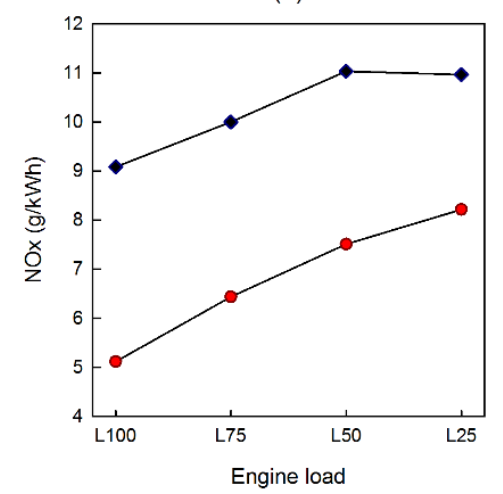

(b)

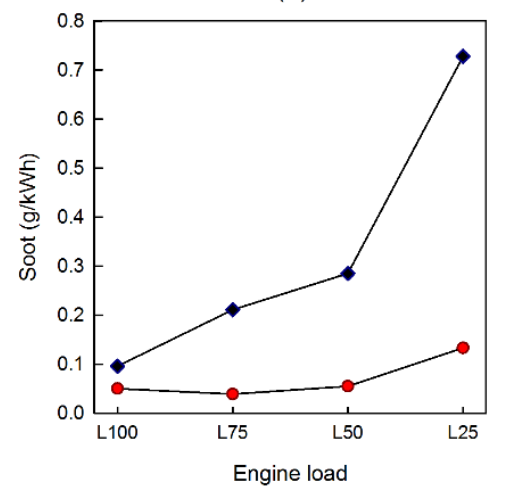

(c)

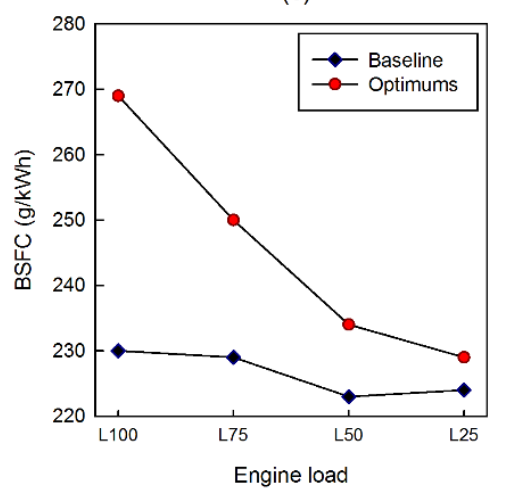

Fig. 11 Comparisons of the sub-objectives of the baseline design and the optimal design of each engine load

Table 4 Sub-objectives comparisons of the baseline design and the optimum design under each engine load

\begin{tabular}{llllllllll}
\hline Load & \multicolumn{2}{l}{ NOx $(\mathrm{g} / \mathrm{kWh})$} & \multicolumn{3}{c}{ Soot $(\mathrm{g} / \mathrm{kWh})$} & \multicolumn{3}{c}{ SFOC $(\mathrm{g} / \mathrm{kWh})$} \\
& $\begin{array}{l}\text { Base- } \\
\text { line }\end{array}$ & $\begin{array}{l}\text { Opti- } \\
\text { mum }\end{array}$ & Status & $\begin{array}{l}\text { Base- } \\
\text { line }\end{array}$ & $\begin{array}{l}\text { Opti- } \\
\text { mum }\end{array}$ & Status & $\begin{array}{l}\text { Base- } \\
\text { line }\end{array}$ & $\begin{array}{l}\text { Opti- } \\
\text { mum }\end{array}$ & Status \\
\hline L100 & 9.09 & 5.11 & $\downarrow 43.8 \%$ & 0.10 & 0.05 & $\downarrow 50.0 \%$ & 230 & 269 & $\uparrow 17.0 \%$ \\
L75 & 10.00 & 6.43 & $\downarrow 35.7 \%$ & 0.21 & 0.04 & $\downarrow 81.0 \%$ & 229 & 250 & $\uparrow 9.2 \%$ \\
L50 & 11.04 & 7.51 & $\downarrow 32.0 \%$ & 0.29 & 0.06 & $\downarrow 79.3 \%$ & 223 & 234 & $\uparrow 4.9 \%$ \\
L25 & 10.97 & 8.22 & $\downarrow 25.0 \%$ & 0.73 & 0.13 & $\downarrow 82.2 \%$ & 224 & 229 & $\uparrow 2.2 \%$ \\
\hline
\end{tabular}

\subsection{Comparisons of the design parameters}

Table 5 represents the design values of the baseline design and the optimum design of each engine load. The optimal designs of each engine load were represented by the OptimumL100, the Optimum-L75, the Optimum-L50 and the Optimum-L25, respectively. From the table, some commonalities from these designs can be drawn below.

(1) Late injection, fuel oil injection happened near the TDC, especially under the full load, the injection happened exactly at the TDC.

(2) Low-swirl, the swirl to be favoured in the optimal design of each load is nearly half of the baseline design. 
(3) Large injection angle, the injection angle of 147 degree is the most popular one among optimal designs.

(4) Slightly smaller nozzle protrusion length, the preferred NPL of each load is slightly smaller than the baseline design.

Table 5 Parameter comparisons of the baseline design and the optimum design of each load

\begin{tabular}{lllll}
\hline Design & SOI (CAD) & SR (-) & SA (deg) & NPL (mm) \\
\hline Baseline & 710 & 1 & 143 & 2.5 \\
Optimum-L100 & 720 & 0.5 & 147.6 & 2.2 \\
Optimum-L75 & 716.6 & 0.7 & 154.2 & 1.6 \\
Optimum-L50 & 714.5 & 0.5 & 147.6 & 2.2 \\
Optimum-L25 & 714.5 & 0.5 & 147.6 & 2.2 \\
\hline
\end{tabular}

\subsection{Comparisons of the detailed combustion process}

The detailed combustion progress comparisons of the loads L100 and L25 were shown in Fig. 12 and Fig. 13 respectively, since the optimal design of the L100 load achieved the largest reduction of NOx emissions and SFOC penalty, whereas the optimum design of the L25 load attained the smallest NOx emissions reduction and SFOC increase. The baseline design (Baseline-L100) and the optimum design (Optimum-L100) under the L100 load are presented by the back and red lines; the baseline design (Baseline-L25) and the optimum design (Optimum-L25) under the L25 engine load are shown by the grey and blue lines. They were compared at both the L100 and L25 roads respectively. In the previous section 4.3, commonalities were found with the late injection, low swirl, large injection angle and slightly smaller nozzle protrusion length. These features affect the combustion process profoundly.

The late injection leaves less time for the fuel-air mixing, and thus the ignition delay period was shortened. A large spray angle results in some fuel aiming at and adhering to the bottom of the piston head and on the surface of the bowl area, since a low swirl is applied. All of these lead to the inadequate fuel-air mixing, as presented by the results of OptimumL100 in Fig. 13. Although approximately the same conditions were happened on the Optimum-L25, the results in Fig. 13 show some differences to those of Optimum-L100. Under low engine loads, the injection duration is much shorter than under high engine loads, thus, the injection kinetic energy and penetration ability are weaker. Therefore, the fuel adheres to the surface of the cylinder head and gathers around the centre crown area, as shown in the bottom right part of Fig. 13. However, under full load, a longer injection duration offers the fuel a larger injection kinetic energy, which results in fuel adhering to the bowl surface. 
The inadequate fuel-air mixing of both the optimum designs of L100 and L25 loads lead to a pent-up rate of heat release, as well as an insufficient combustion, by comparing to the baseline on the same loads, respectively. Therefore, the maximum temperature in the combustion chamber achieved in these cases are lower than the baseline conditions. The lower maximum temperatures discourage the NOx formation. That are the main reasons for the low NOx emissions achieved in the optimal designs, evidence can be found in Fig. 12 (c), (d) and (a). Interestingly, higher soot formation rates are seen in the baseline designs of both the L100 and L25 engine loads, as opposed to the baseline designs because of inadequate mixing, as shown in Fig. 12 (b). However, high soot formation rates do not necessarily mean high soot emissions in the end thanks to the high rate of soot oxidation offered by the high temperature in the afterburning process. The high temperature in the afterburning process is the side benefit of the late injection because more fuel was burned following the combustion stage. In addition, an increased fuel consumption was seen in the optimal designs as punishment negative results of insufficient combustion. 
(a)

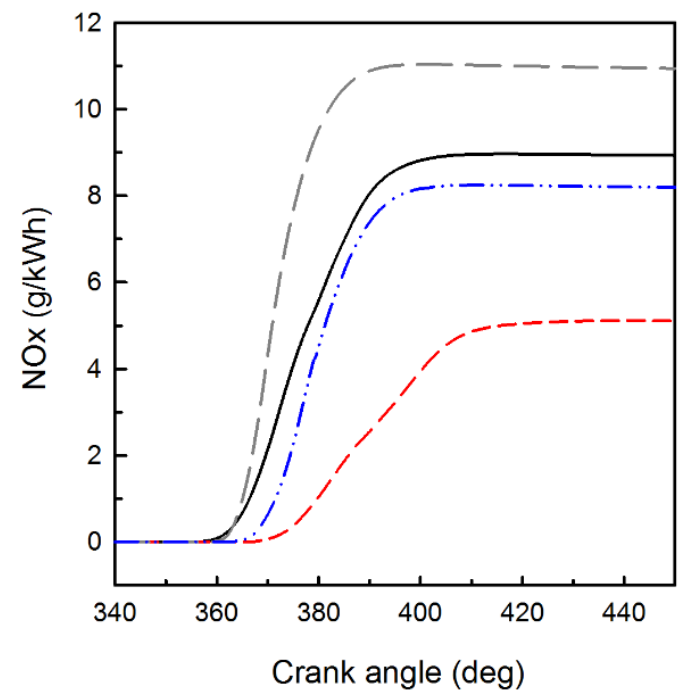

(c)

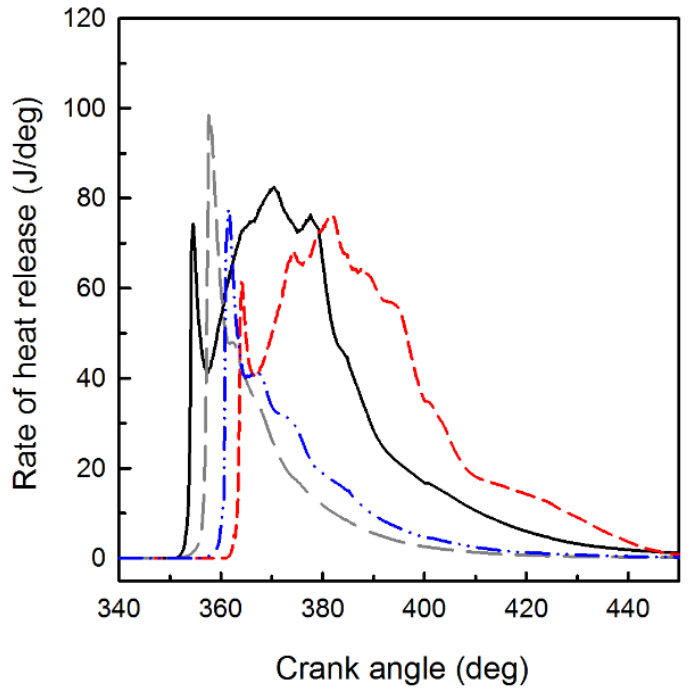

(b)

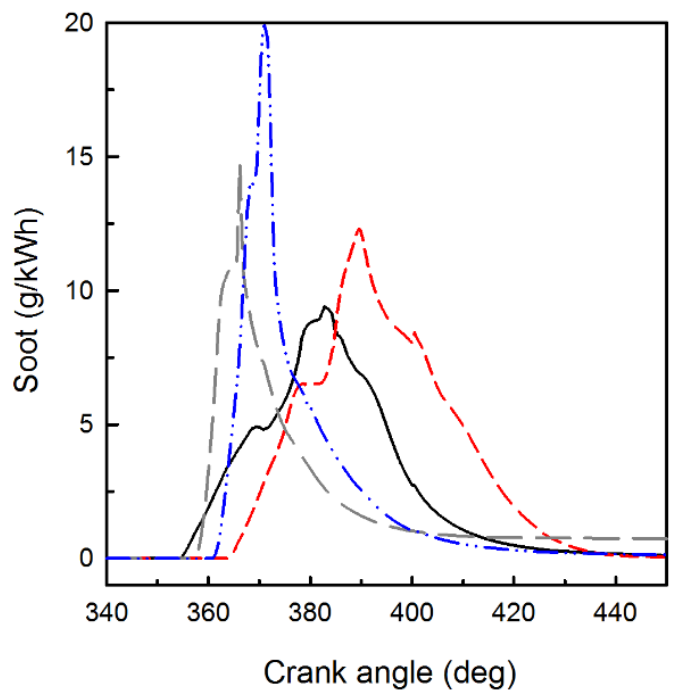

(d)

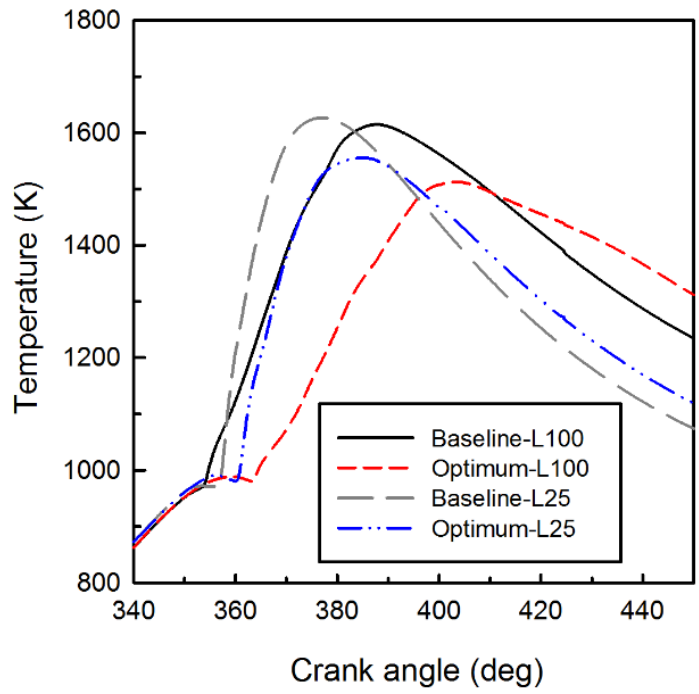

Fig. 12 Detailed combustion process comparisons 


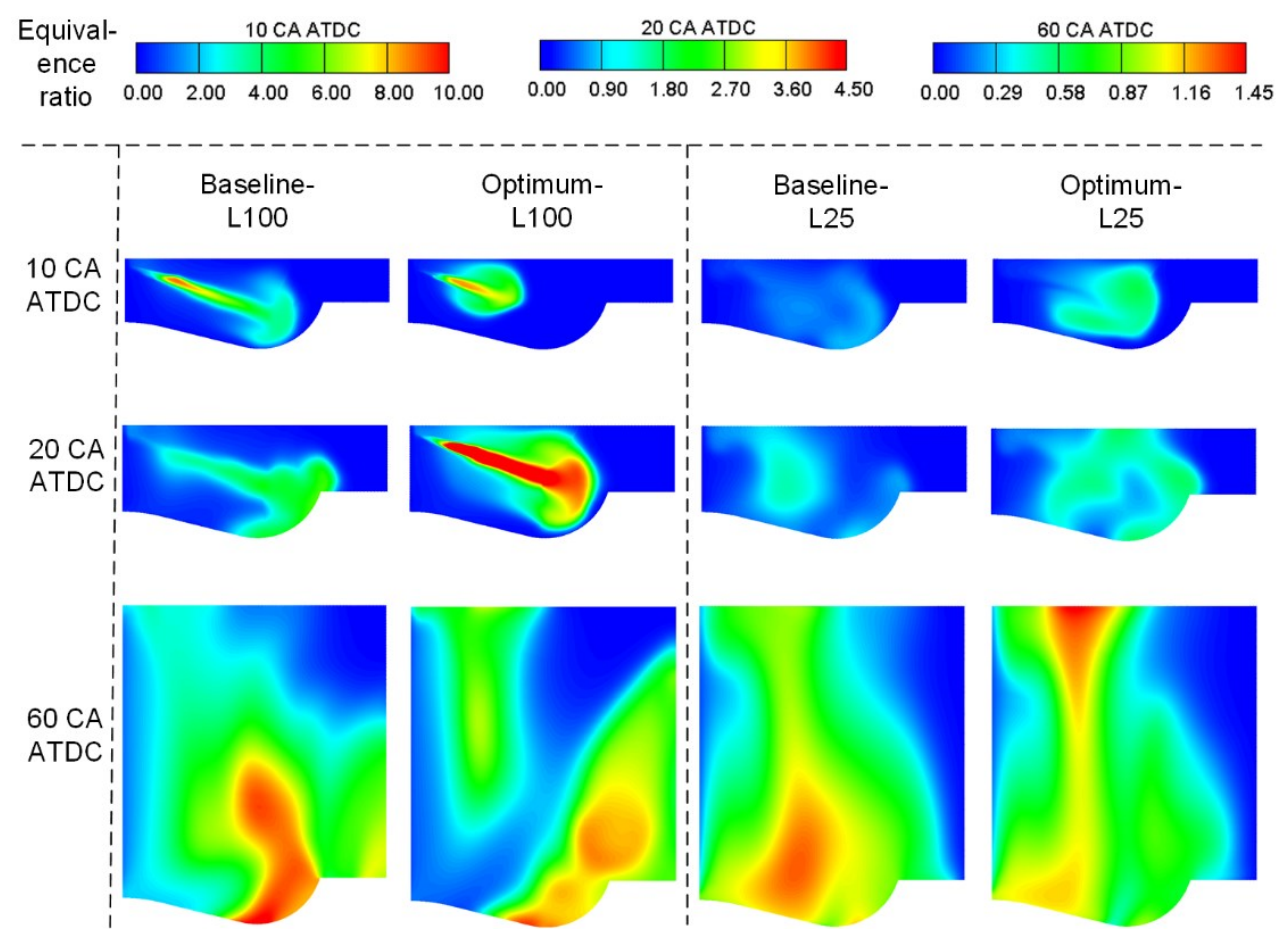

Fig. 13 Fuel-air equivalence ratio comparisons

\subsection{Effects of the design parameters on the objective}

The optimisation data from the L100 engine load was used to study the effects of the design parameters on the objective, which are shown by the RSM functions in Fig. 14. In the figure, only the examined parameter varies, while the other parameters remain the same as the baseline value. From the figure, the objective obviously decreases with the increase in the SOI and NPL, and increases along with the SR. The objective reaches a bottom value when the SA is $139 \mathrm{deg}$ and increases slightly when it decreases or increases. Another fact indicating that the SOI and the SR have more significant impacts on the objective than the NPL and SA due to larger scopes of the objective variation were seen in Fig. 14 (a) and (b).

Fig. 15 and Fig. 16 are the RSM charts of the SOI and SR, NPL and SA, respectively. The bright diamond points in the figures represent the Baseline-L100. Fig. 15 disclosed that a large SOI together with a small SR can reduce the objective significantly and vice versa. Fig. 16 indicates that a large NPL with a small SA or a small NPL with a large SA contribute to the reduction of the objective. Conversely, a small NPL together with a small SA or a large NPL combined with a large SA worsen the objective. 
(a)

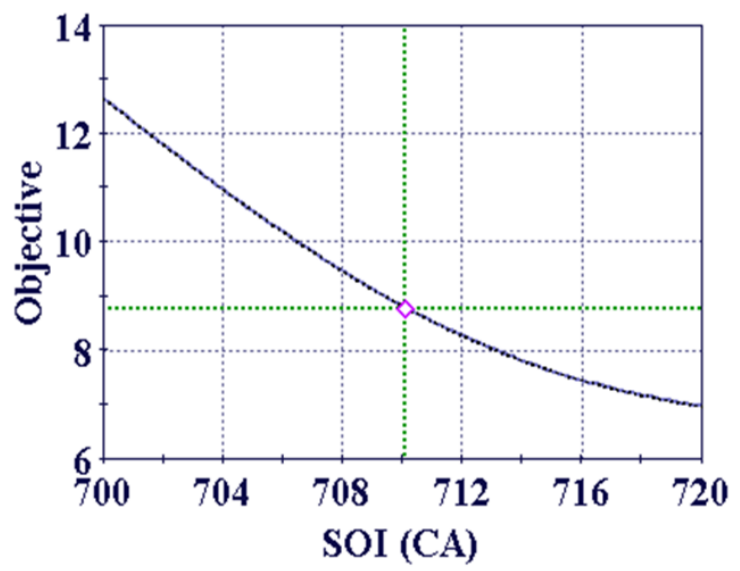

(c)

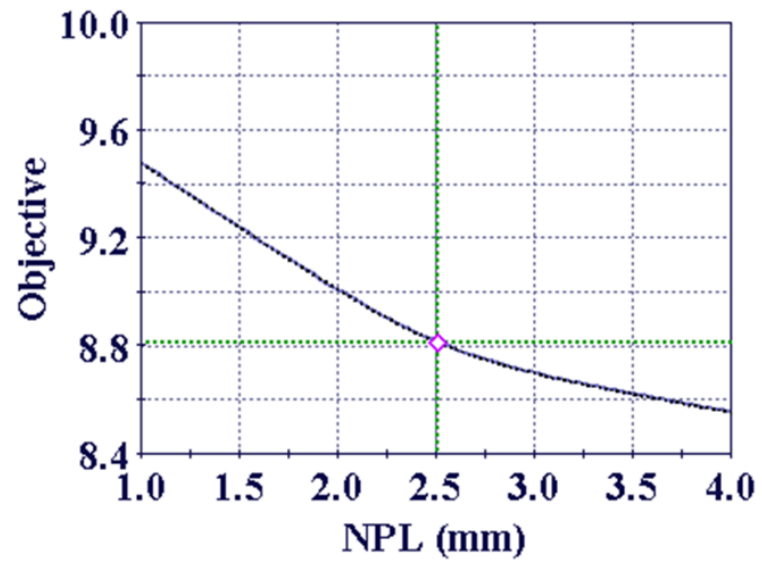

(b)

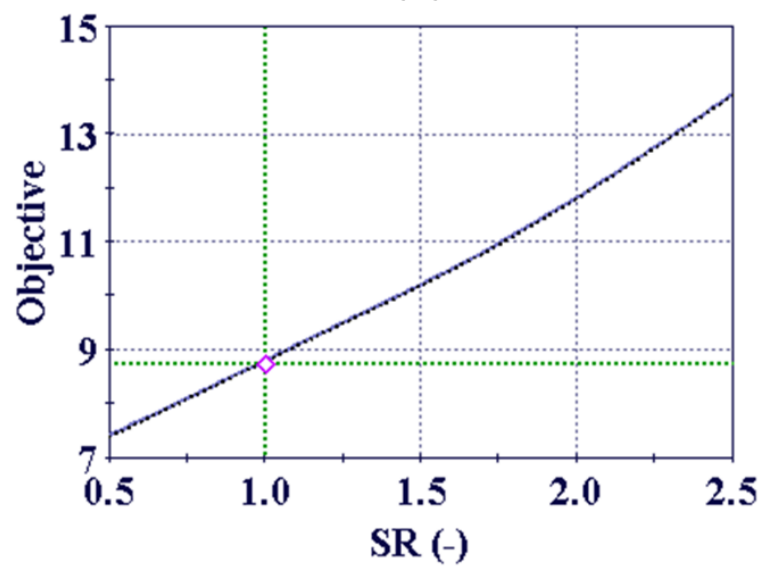

(d)

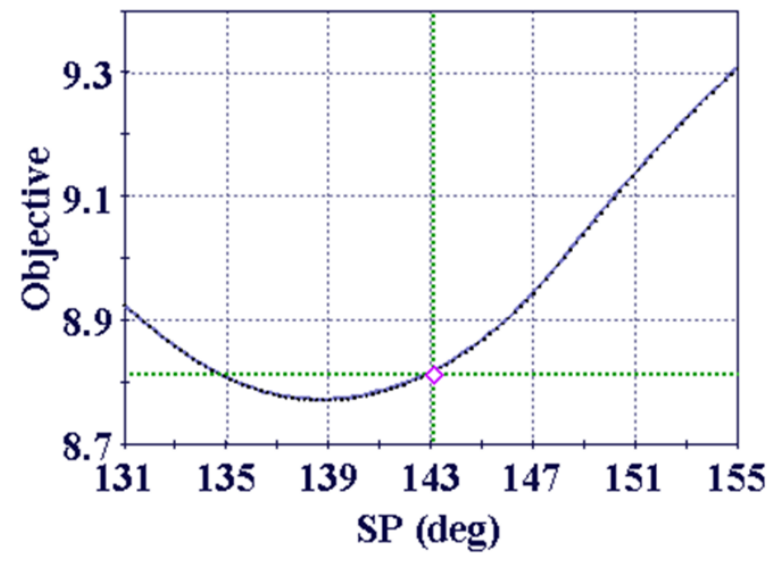

Fig. 14 Effects of the design parameters on the objective 


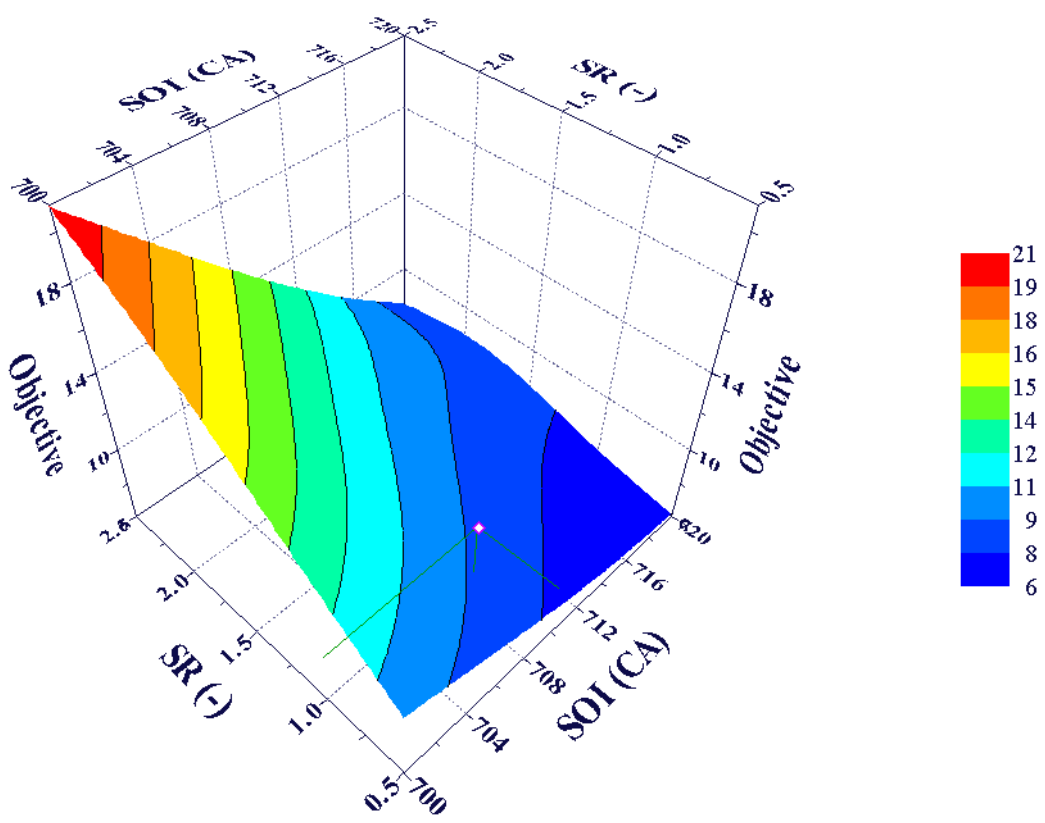

Fig. 15 RSM surface chart of the SOI and the SR

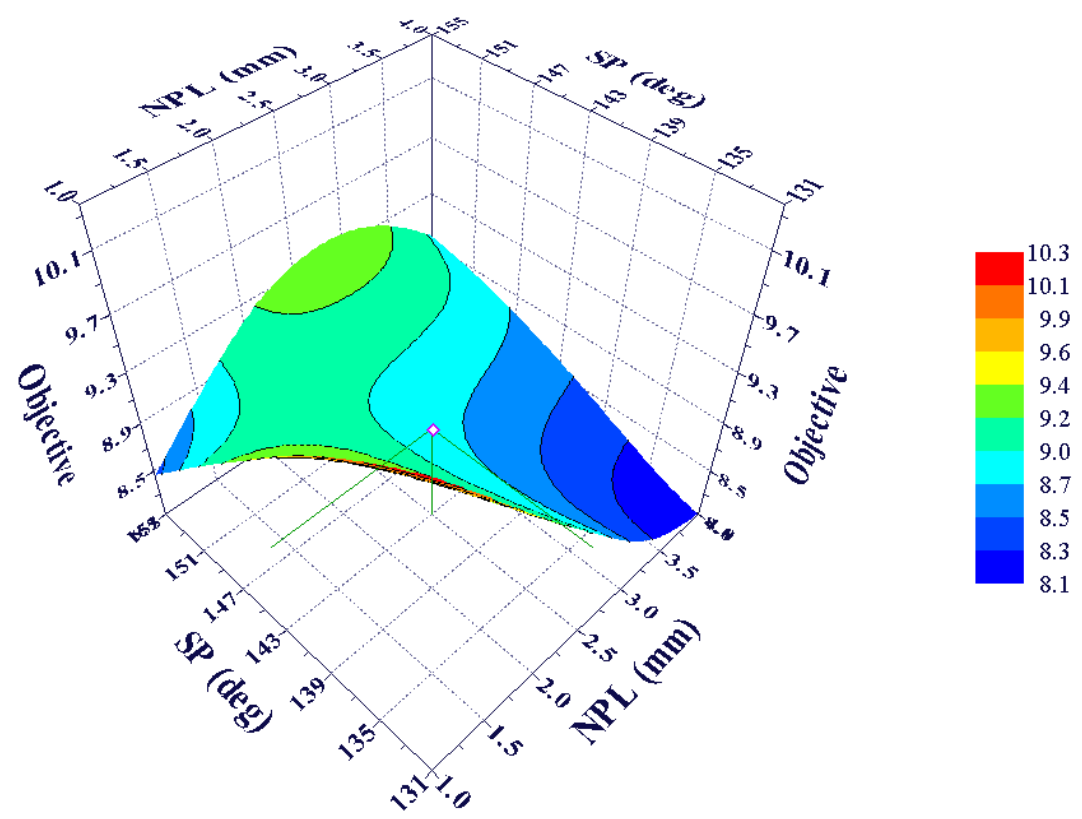

Fig. 16 RSM surface chart of the NPL and the SA

\section{Conclusions}

This paper adopted and evaluated the Latin hypercube design along with the NLPQL algorithm in order to optimise the four injection-related design parameters match with a combustion chamber of a marine medium-speed diesel engine under four different engine loads. Comparisons of the objectives, sub-objectives, design parameters and detailed 
combustion process were carried out. The differences and commonalities of the optimums in four engine loads were also inspected and a detailed combustion process comparison of the optimum and the baseline was conducted under L100 and L25 engine loads respectively. Finally, the effects of the design parameters on the objective were studied by RSM. The main conclusions were drawn below.

(1) The maximum optimisation process was ended with less than 64 runs and the optimum under each load were found with the best trade-off between the NOx emissions and the soot emissions, although a high SFOC was always identified along with these optimums. The efficiency of the NLPQL algorithm is proven.

(2) Better optimisation qualities were found in high engine loads than in low engine loads. In other words, the optimisation process of the L100 and L50 engine loads searched around an area where an optimum with the best trade-off may locates with a larger possibility. However, under low engine loads, the optimisation history and distribution shows that the optimisation process is tilted toward the reduction of the NOx emissions, whereas the soot emissions were neglected in some extent.

(3) The largest NOx emissions reduction and the heaviest fuel economy penalty were seen with the optimum of the L100 engine load. However, the lowest NOx emission reduction along with a slight increase of the SFOC were spotted with the optimum of the L25 engine load.

(4) Commonalities of the optimal designs of the four engine loads were found with the late injection, low swirl, large injection angle and slightly smaller nozzle protrusion length.

(5) The SOI and SR have larger influences on the objective than the NPL and SA. A large SOI together with a small SR can reduce the objective significantly and vice versa. A large NPL with a small SA or a small NPL with a large SA contribute to the reduction of the objective. However, a small NPL together with a small SA or a large NPL combined with a large SA worsen the objective.

\section{Acknowledgments}

Authors are grateful to the Wuhan University of Technology for providing experimental facilities and test data. We also appreciate the Department of Naval Architecture and Marine Engineering of University of Strathclyde for the calculation support on the project.

\section{Declaration of conflicting interests}

The authors declare that there is no conflict of interest.

\section{Funding}


This work was supported by the project 'Engineering Development of a Medium-Speed Dual Fuel Engine (Ministry of Industry and Information Technology NO. (2013) 412, 2)' from China and the project 'An Investigation into the Characteristics of High-pressure Common Rail Injection System' from Lloyd's Register of Shipping of UK.

\section{Reference}


1. Taghavifar H, Khalilarya S, Jafarmadar S. Engine structure modifications effect on the flow 
behavior, combustion, and performance characteristics of DI diesel engine. Energy Convers Manag 2014; 85: 20-32.

2. Mobasheri R and Peng Z, Analysis of the effect of re-entrant combustion chamber geometry on combustion process and emission formation in a HSDI diesel engine. SAE Technical Paper, 2012-01-0144.

3. Park S. Optimization of combustion chamber geometry and engine operating conditions for compression ignition engines fueled with dimethyl ether. Fuel 2012; 61-71.

4. Kim M, Liechty M, Reitz RD. Application of micro-genetic algorithms for the optimization of injection strategies in a heavy-duty diesel engine. SAE Technical Paper, 2005-01-0219.

5. Ge HW, Shi Y, Reitz RD. Optimization of a HSDI diesel engine for passenger cars using a multi-objective genetic algorithm and multi-dimensional modelling. SAE Int J Engines 2009; 2(1): 691-713.

6. Shi Y and Reitz RD. Optimization study of the effects of bowl geometry, spray targeting, and swirl ratio for a heavy-duty diesel engine operated at low and high load. Int $J$ Engine Res 2008; 9: 325-346.

7. Ge HW, Shi Y, Reitz RD. Reitz. Heavy-duty diesel combustion optimization using multiobjective genetic algorithm and multi-dimensional modelling. SAE Technical Paper, 2009-010716 .

8. Beatrice C, Napolitano P, Guido C. Injection parameter optimization by DoE of a light-duty diesel engine fed by Bio-ethanol/RME/diesel blend. Appl Energy 2014; 113: 373-384.

9. Pandian M, Sivapirakasam SP, Udayakumar M. Investigation on the effect of injection system parameters on performance and emission characteristics of a twin cylinder compression ignition direct injection engine fuelled with pongamia biodiesel-diesel blend using response surface methodology. Appl Energy 2011, 88: 2663-2676.

10. Chen Y, Lv L. The multi-objective optimization of combustion chamber of DI diesel engine by NLPQL algorithm. Appl Therm Eng 2014; 73: 1332-1339.

11. Navid A, Khalilarya S, Taghvifar H. Comparing multi-objective non-evolutionary NLPQL and evolutionary genetic algorithm optimisation of a DI diesel engine: DoE estimation and creating surrogate model. Energy Convers Manag 2016; 126: 385-399.

12. Hu N, Zhou P, Yang J. Comparison and combination of NLPQL and MOGA algorithms for a marine medium-speed diesel engine optimisation. Energy Convers Manag 2017; 133: 138-152.

13. Lotfan S, Akbarpour Ghiasi R, Fallah M, Sadeghi MH. ANN-based modeling and reducing dual-fuel engine's challenging emissions by multi-objective evolutionary algorithm NSGA-II. Appl Energy 2016, 175: 91-99.

14. Rezaei J, Shahbakhti M, Bahri B, Abdul Aziz A. Performance prediction of HCCI engines with oxygenated fuels using artificial neural networks. Appl Energy 2015, 138: 460-473. 
15. Ali OM, Mamat R, Najafi G, Yusaf T, Ardebili SMS. Optimization of biodiesel-diesel blended fuel properties and engine performance with ether additive using statistical analysis and response surface methods. Energies 2015; 8(12): 14136-14150.

16. Camarillo MK, Stringfellow WT, Hanlon JS, Watson KA. Investigation of selective catalytic reduction for control of nitrogen oxides in full-scale dairy energy production. Appl Energy 2013; 106: 328-336.

17. Fire software users guide, AVL List GmbH. Design of Experiments and Optimization Users Guide, 02/2013 ed. AVL List GmbH: Graz, Austria, 2014.

18. Schittkowski K. NLPQL: A Fortran subroutine solving constrained nonlinear programming problems. Ann Oper Res 1985; 5(6): 485-500.

19. Hanjalic K, Popovac M, Hadziabdic M. A robust near-wall elliptic relaxation eddyviscosity turbulence model for CFD. Int J Heat Fluid Flow 2004; 25: 1047-1051.

20. Popovac M and Hanjalic K. Compound wall treatment for RANS computation of complex turbulent flows and heat transfer. Flow Turbul Combustion 2007; 78: 177-202.

21. Issa RI. Solution of the implicit discretised fluid flow equations by operator splitting. $J$ Comput Phys 1985; 62: 45-60.

22. Emans M. AMG for Linear Systems in Engine Flow Simulations. PPAM 2009, Part II, LNCS 6068; 350-359.

23. Dukowicz JK. Quasi-steady droplet change in the presence of convection. Los Alamos Scientific Laboratory. LA7997-MS.

24. Liu A, Mather D, Reitz RD. Modelling the effects of drop drag and breakup on fuel sprays, SAE Technical Paper 1993; DOI: 10. 4271/930072.

25 . Reitz RD, Modelling atomization processes in high-pressure vaporizing sprays, Atomization and Spray Technology 1987; 3: 309-337.

26. Naber JD and Reitz RD. Modelling engine spray/wall impingement. SAE Technical Paper, 880107.

27. Cabrera E and Gonzalez JE., Heat flux correlation for spray cooling in the nucleate boiling regime. Exp Heat Transf 2003; 16: 19-44.

28. Spalding DB. Mixing and chemical reaction in steady confined turbulent flames. Symp (Int) Combust 1971; 13(1): 649-657.

29. Magnussen $\mathrm{BF}$ and Hjertager BH. On mathematical modelling of turbulent combustion with special emphasis on soot formation and combustion. Symp (Int) Combust 1997; 16(1): 719-729.

30. Zeldovich YA, Frank-Kamenetskii D, Sadovnikov P. The oxidation of nitrogen in combustion and explosions. Publishing House of the Academy of Sciences of USSR 1947.

31. Wang $\mathrm{H}$ and Frenklach M. A detailed kinetic modelling study of aromatics formation, growth and oxidation in laminar premixed ethylene and acetylene flames. Combust Flame 1997; 110: $173-221$. 
32. Apple J, Bockhorn H, Frenklach M. Kinetic modelling of soot formation with detailed chemistry and physics: laminar premixed flames of C2 hydrocarbons. Combust Flame 2000; 121: 122-136.

33. Balthasar M and Frenklach M. Detailed kinetic modelling of soot aggregate formation in laminar premixed flames. Combust Flame 2005; 140: 130-145.

34. Abraham $\mathrm{J}$, What is adequate resolution in numerical computations of transient jets? $S A E$ Technical Paper, 1997-00-51. 